\title{
Monopolistic Security Design in Finance Economies*
}

\author{
Karl Schmedders ${ }^{\dagger}$ \\ Kellogg Graduate School of Management \\ Northwestern University
}

March 14, 2000

\footnotetext{
${ }^{*}$ I am very grateful to Ken Judd and Larry Jones for many discussions on this subject. I thank audiences at the Summer 1999 meeting of the Econometric Society in Madison, at Stanford University, and at the University of California at San Diego for helpful comments. Detailed comments by Ken Judd on an earlier draft greatly improved the presentation of the results. All remaining errors are mine.

${ }^{\dagger}$ mailing address: KGSM-MEDS 5th floor, 2001 Sheridan Rd, Evanston, IL 60208; phone: 847-491-5158; fax: 847-467-1220; e-mail: k-schmedders@kellogg.nwu.edu
} 


\begin{abstract}
The purpose of this paper is to analyze endogenous asset innovation by an entrepreneurial exchange owner in a partial equilibrium model of incomplete security markets with financial transaction fees. A monopolistic market maker has the technology to introduce new securities into the economy and charge investors transaction fees if they trade on the exchange. The market maker's objective is to choose the security and transaction fee that maximize profits when opening the exchange.

We compute the effects of asset innovation for the case of an option exchange introducing an option on a stock index. In the first set of economies agents with heterogeneous levels of risk aversion trade securities to achieve some risk sharing. In the second set of economies agents have identical risk aversion but heterogeneous beliefs which leads to trading due to the desire for portfolio re-balancing. In both types of models the introduction of the profit-maximizing option leads to a decrease of the prices of established securities. Typically small heterogeneity of beliefs leads to substantial more trading volume in the option than reasonable differences among levels of risk aversion.

Our computational approach allows us to examine some previous results in the theoretical literature for heterogeneous-beliefs models about the effects of an option introduction. We show that these results about options leading to a price increase of the underlying stock depend on some very strong assumptions on the parameters and are quantitatively negligible. Typically an opposite result, namely a price decrease of the underlying stock, of much larger quantitative magnitude holds.
\end{abstract}




\section{Introduction}

The last thirty years have witnessed an astronomical rise in the number of securities traded on financial markets and in the transaction volume on these markets. Many financial innovators, such as governments, banks, firms and exchange companies have contributed to this development. While these innovators have been driven by a variety of motives to introduce new financial securities, two motives appear to dominate: the desire of investors to increase their risk-sharing opportunities and the objective of entrepreneurial market makers to make profits by charging transaction fees. Allen and Gale (1994) provide a detailed discussion of a variety of motives for financial innovators to introduce new financial securities. They argue that the desire of agents to improve risk-sharing opportunities is the most important driving force of financial innovation. In particular they view the introduction of a financial security as a step to move incomplete markets closer to a system of complete markets (Van Horne (1985)). They also recognize other important benefits of financial innovation such as the reduction of transaction costs (Merton (1990)) and the opportunity for market makers to earn temporary monopolistic profits (Silber (1985)).

A growing economic literature attempts to build a theoretical framework for security design in incomplete financial markets. Research in general equilibrium theory focuses on the spanning role of new securities. The objectives of this research effort are to study how new securities affect the market span of all financial assets, to compare the effects of different sets of securities, and to explain which financial structures would be preferred by rational agents in the model. However, Duffie and Rahi (1995) complain that

while there are several results providing conditions for the existence of equilibrium with innovation, the available theory has relatively few concrete normative or predictive results.

The purpose of this paper is to analyze endogenous asset innovation through a profit-maximizing market maker in a model of incomplete security markets with transaction fees on financial markets. Following the typical two-stage setup (Duffie and Rahi (1995)) of security innovation models we proceed in two steps. First, we define equilibrium in a model of a two-period finance economy with asset transaction fees and a fixed set of securities. Secondly, we introduce a monopolist who has the technology to introduce new securities, and who has the right to charge proportional transaction fees for transactions of the new securities. The market maker chooses the securities and 
transaction fees to maximize profits from opening the exchange. We analyze the effects of security innovation in parameterized versions of our model. A computational approach is necessary since there are no interesting models with closed-form solutions. We focus on economies with a market maker operating an option exchange introducing a single option on a stock (index). We compute optimal pairs of option payoffs (determined by the strike price) and transaction fees for the market maker. Furthermore we determine the welfare effects of the new option and perform comparative statics exercises on the impact of the option innovation on the prices and the trading volume of the existing assets.

Our general model is similar to the model by Hara (1995) who studies a general equilibrium model of endogenous asset formation in which a monopolistic designer can create a finite number of assets to maximize commission revenues. In order to obtain closed-form results consumers are restricted to have mean-variance utility functions. Hara (1995) emphasizes an important feature of his (and our) model, namely that a market maker simultaneously choosing several assets may have an incentive to introduce assets such that the resulting security structure is arbitrarily close to redundancy. The supremum of the total commission revenues, over the choice set of proportional transaction fees and payoff structures of a fixed number of assets, cannot be achieved. Hara (1995) proves that this problem does not occur in his model if the number of innovated securities is at most 2. For our computational analysis of the model of an option exchange introducing a single option in a model with a bond and a stock we therefore do not need to be concerned with any existence problems.

Our computational analysis of the effects of an option introduction resembles the general equilibrium analysis of option and stock market interactions by Detemple and Selden (1991). They consider a general equilibrium model with incomplete markets in which three assets are available: a stock, a call option on the stock, and a bond. They show that the stock price depends generically on the strike price of the option. In a specialized version of their model with no first-period consumption and quadratic utility functions and two types of agents with differing beliefs, they find that the option introduction increases the equilibrium stock price. Although Detemple and Selden (1991) do not consider transaction fees one expects to find a similar result in our model. We show, however, that their result of the price effect of an option introduction depends very crucially on their assumptions on the agents' beliefs. Even if those assumptions are satisfied, the magnitude of 
their proven effect is minuscule (price increase of less than $10^{-3} \%$ ) in our model. On the contrary, for most strike prices of the call option their assumptions on agents' beliefs are not satisfied and a stock price decrease, not increase, of much larger magnitude occurs (price decrease of more than 2 $\%)$.

Bisin (1998) presents a general equilibrium model where several imperfectly competitive market makers play a game to determine both the number of assets and their payoffs as well as the bidask spreads they charge investors for trading the assets. The entrepreneurs face both fixed and variable transaction costs for the introduction and intermediation of each asset making financial markets endogenously incomplete. Once the assets and bid-ask spreads are chosen, an equilibrium is determined in a financial markets (two-period GEI) model. All securities have nominal payoffs and contrary to incomplete market models with exogenously specified asset payoffs the equilibria do not exhibit real indeterminacy.

The seminal paper by Duffie and Jackson (1989) has been a major influence for many papers in financial innovation. Duffie and Jackson (1989) consider a one-period model of a futures exchange with fixed transaction costs on asset trades. The exchange's objective is to design an optimal futures contract in order to maximize transaction volume and so their revenues. In order to simplify the analysis all agents are assumed to have mean-variance utility functions. Duffie and Jackson (1989) give necessary condition on the structure of the new financial contract to be volume maximizing. With zero transaction costs they also obtain sufficient conditions. As Allen and Gale (1994, chapter 4) point out, a big drawback of the model is that the transaction costs are exogenous. It is more realistic to assume that the exchange owner can decide both the structure of the new asset and the transaction fee. We include this feature in our model, and our computational analysis shows that the transaction fee has a significant impact on the revenues of the exchange owner. In particular, we detect a connection between the choice of asset structure and the fee that maximizes the exchange's revenue.

Allen and Gale (1994) consider a process of financial innovation in which firms can issue different assets against their future income stream. Financial innovation is thus a part of the firms' policies to maximize profits. Although papers in the general equilibrium literature on financial innovation typically are not concerned with aspects of corporate policy the basic framework of Allen and Gale (1994) has been widely adapted. Pesendorfer (1995) presents a similar innovation process in which perfectly competitive intermediaries can issue new securities against collateral in form of 
other standard securities. Both innovation costs and short-sale constraints are important in these models with collateral. We include transaction costs in our model description but omit short-sale constraints. However, such constraints could be easily incorporated both in the model and the computational analysis.

Before we continue a few words of caution are necessary. In this paper we consider as the only motives for financial innovation the desire of investors to have increased risk-sharing opportunities and the objective of entrepreneurs to make profits through the introduction of new securities. Of course, there are many other reasons that are important. The surveys by Allen and Gale (1994) and Duffie and Rahi (1995) mention many other motives, among them, the desire to circumvent regulations and taxation, a reaction to a change in accounting standards, corporate control issues within a firm, a firm's objective to raise capital, or the desire to change prices of other assets. Corresponding to the many different aspects of financial innovation there exists a continuously growing literature on the subject. We are not concerned with any of these issues and refer the interested reader to the surveys by Allen and Gale (1994) and Duffie and Rahi (1995) and the many citations therein. We concentrate on the spanning role of securities. This restriction paired with the parameterizations of our model allows us to make concrete predictions about the impact of a security introduction.

The remainder of the paper is organized as follows: Section 2 describes a partial equilibrium model of asset innovation. In Section 3 we specialize the model of the market maker and consider an option exchange introducing a single option. Section 4 reports computational results for models with homogeneous beliefs. In Section 5 we examine the innovation effects in the presence of heterogeneous beliefs. We finish the paper with some concluding remarks in Section 6 .

\section{A Partial Equilibrium Model of Security Innovation}

In this section we introduce the general version of our partial equilibrium model of asset innovation. Following the typical two-stage setup (Duffie and Rahi (1995)) of security innovation models we proceed in two steps. First, we describe our model of a finance economy for a given set of securities with asset transaction fees. Secondly, we introduce a monopolist who has the technology to introduce and intermediate new securities, and who has the right to charge proportional transaction fees for transactions of the new securities. The introduction of securities leads to both fixed and 
variable costs. The market maker correctly anticipates the equilibrium trades and prices given her choice of new securities and transaction fees. Her objective is to maximize profits by choosing the best combinations of new securities and corresponding transaction fees.

The market maker must give investors an incentive to trade the new asset in order to receive revenues from operating the exchange. One possibility to create such an incentive is to offer a redundant asset with a payoff structure that could be copied through a portfolio of already existing securities, however, only at considerable transaction costs. Mutual funds are a prime example of such a financial instrument. Pesendorfer (1995) allows for the introduction of redundant assets and shows that in his model the creation of such assets can be an equilibrium property. A second and according to Allen and Gale (1994) much more desirable possibility would be the introduction of a new asset that improves the investors' risk-sharing opportunities. Such an asset would allow investors to insure against a previously uninsured risk and they might be willing to pay considerable transaction fees for trading such a new security. In order to rule out the introduction of redundant assets we assume that agents pay no transaction fees on already existing assets. Therefore, the market maker has to introduce an asset that increases the asset span in order to have any hope to charge transaction fees from the investors. In this setup we can interpret the amount of transaction fees agents are willing to pay as a measure of their desire for additional spanning.

\subsection{Finance Economy with Transaction Costs}

The standard model of a Stochastic Finance Economy describes an exchange economy over two periods $t=0,1$ with uncertainty over the state of nature in period $t=1$. At time $t=0$ the economy is in state $s=0$ which is known by each of the $\mathrm{H}$ types of agents $(h=1, \ldots, H, H<\infty)$ participating in the economy. But it is not known which of the $S$ possible states $y=1, \ldots, S$ at time $t=1$ will occur.

In each state $y=0,1, \ldots, S$ there is a single (perishable) consumption good. Each agent $h$ chooses a consumption vector $c^{h}=\left(c_{0}^{h}, \ldots, c_{S}^{h}\right) \in \mathbb{R}_{++}^{S+1}$ where $c_{y}^{h} \in \mathbb{R}_{++}$denotes the consumption choice for state $y$. Agent $h$ is characterized by an initial endowment vector, $e^{h}=\left(e_{0}^{h}, \ldots, e_{S}^{h}\right) \in$

$\mathbb{R}_{++}^{S+1}$, and his preferences. These are represented by a utility function $u^{h}: \mathbb{R}_{++}^{S+1} \rightarrow \mathbb{R}$ satisfying the standard assumptions of smooth preferences, that is, $u^{h}$ is strictly increasing, strictly quasiconcave and twice continuously differentiable. Moreover, the closure of the indifference curves of $u^{h}$ lies in $\mathbb{R}_{++}^{S+1}$. 
The agents face a separate budget constraint in every state $y$. In order to transfer wealth between time periods and states of nature agents can buy a portfolio of securities at time $t=0$. There are two types of securities. First, there is a finite number $J$ of "established" assets that can be traded without transaction fees. Second, there is a finite number $I$ of "new" securities, which have just been introduced by a market maker. (In our applications the just introduced security is a derivative on an established asset.) Agents have to pay transaction fees if they want to trade these assets. Without loss of generality all $J+I$ assets are in zero net supply. We always consider incomplete markets, that is, $J+I<S$.

Each established asset $j$ pays a nonnegative dividend $a_{y}^{j} \in \mathbb{R}_{0}^{+}$in state $y \geq 1$, and each new asset $i$ pays a nonnegative dividend $d_{y}^{i} \in \mathbb{R}_{0}^{+}$in state $y \geq 1$. The asset price of established asset $j$ (new asset $i$ ) in state $y=0$ is denoted by $p^{j}\left(q^{i}\right)$. We define $p=\left(p^{1}, p^{2}, \ldots, p^{J}\right) \in \mathbb{R}^{J}$ to denote the vector of prices for the established assets at time 0 . The vector $q \in \mathbb{R}^{I}$ is defined analogously. At time $t=0$ agent $h$ chooses asset transactions $\theta^{h} \in \mathbb{R}^{J}$ of the $J$ established assets. If $\theta^{h, j}>0\left(\theta^{h, j}<0\right)$ then the agent holds a long (short) position in asset $j$. In addition, the agent chooses asset transactions $\left(\vartheta^{+, h}, \vartheta^{-, h}\right) \in \mathbb{R}_{+}^{I} \times \mathbb{R}_{+}^{I}$ of the $I$ new assets, where $\vartheta^{+, h}$ denotes the amount of asset purchases and $\vartheta^{-, h}$ denotes the asset short sales of the new securities. Whenever agent $h$ conducts a transaction on the new asset markets he must pay a proportional transaction fee. The per-unit transaction fee for buying (selling) asset $i$ is denoted by $k^{+, i} \in \mathbb{R}_{+}\left(k^{-, i} \in \mathbb{R}_{+}\right)$. Buying $\vartheta^{+, h, i}$ units of security $i$ having a price $q^{i}$ leads to expenditures of $\left(q^{i}+k^{+, i}\right) \vartheta^{+, h, i}$ for the agent. Similarly, selling $\vartheta^{-, h, i}$ units of asset $i$ leads to revenues of $\left(q^{j}-k^{-, i}\right) \vartheta^{-, h, i}$. Finally, we define $\theta^{h}=\left(\theta^{h, 1}, \theta^{h, 2}, \ldots, \theta^{h, J}\right) \in \mathbb{R}^{J}$. The vectors $\vartheta^{+, h}$ and $\vartheta^{-, h}$ are defined analogously.

The exogenous parameters defining an economy

$$
(\mathcal{E})=\left(\mathcal{E}\left(\left(u^{h}, e^{h}\right)_{h=1, \ldots, H} ;\left(a^{j}\right)_{j=1, \ldots, J} ;\left(d^{i}\right)_{i=1, \ldots, I} ; k^{+}, k^{-}\right)\right)
$$

are the agents' utility functions $\left(u^{h}\right)_{h=1, \ldots, H}$ and endowments $\left(e^{h}\right)_{h=1, \ldots, H}$, the dividend vectors $\left(a^{j}\right)_{j=1, \ldots, J}$ and $\left(d^{i}\right)_{i=1, \ldots, I}$, and the vector of proportional transaction fees $k$. In a slight abuse of notation we will denote the set of agents and the two sets of assets by $H, J$, and $I$ respectively. Next, we define a notion of equilibrium for the economy $(\mathcal{E})$.

\section{Definition 1 (Competitive Equilibrium)}

A competitive equilibrium for a stochastic finance economy with transaction costs $(\mathcal{E})$ is defined as a collection of consumption allocations $\left(\bar{c}^{h}\right)_{h=1, \ldots, H}$, asset transactions $\left(\bar{\theta}^{h}\right)_{h \in H}$ and $\left(\bar{\vartheta}^{+, h}, \bar{\vartheta}^{-, h}\right)_{h \in H}$, and asset prices $\left(\bar{p}^{j}\right)_{j \in J}$ and $\left(\bar{q}^{i}\right)_{i \in I}$ satisfying the following conditions: 
(1) The vectors $\left(\bar{c}^{h}\right)_{h \in H},\left(\bar{\theta}^{h}\right)_{h \in H},\left(\bar{\vartheta}^{+, h}, \bar{\vartheta}^{-, h}\right)_{h \in H}$ solve the utility maximization problems for all agents $h \in H$ :

$$
\begin{array}{cl}
\max _{c, \theta, \vartheta^{+}, \vartheta^{-}} & u^{h}(c) \\
s . t . & c_{0}=e_{0}^{h}-\bar{p} \theta-\left(\bar{q}+k^{+}\right) \vartheta^{+}+\left(\bar{q}-k^{-}\right) \vartheta^{-} \\
& c_{y}=e_{y}^{h}+a_{y} \theta+d_{y}\left(\vartheta^{+}-\vartheta^{-}\right) \quad \text { for all } y \geq 1 \\
& \vartheta^{+} \geq 0, \vartheta^{-} \geq 0
\end{array}
$$

(2) All security markets clear:

$$
\begin{aligned}
\sum_{h \in H} \bar{\theta}^{h} & =0 . \\
\sum_{h \in H}\left(\bar{\vartheta}^{+, h}-\bar{\vartheta}^{-, h}\right) & =0 .
\end{aligned}
$$

The monotonicity of the utility functions allows us to write the budget constraints immediately as equations. The agents' utility maximization problems are convex programming problems so that the first-order conditions are both necessary and sufficient for optimality. Denote the Lagrange multipliers for the inequality constraints $\vartheta^{+, h, i} \geq 0$ and $\vartheta^{-, h, i} \geq 0$ by $\lambda^{+, h, i}$ and $\lambda^{-, h, i}$, respectively. Then, the equilibria of the economy $(\mathcal{E})$ are given by the solutions to the following equations and inequalities.

$$
\begin{aligned}
\partial_{c_{0}} u^{h}(c) p^{j}-\sum_{y=1}^{S} \partial_{c_{y}} u^{h}(c) a_{y}^{j} & =0 \quad \text { for } h \in H, j \in J \\
\partial_{c_{0}} u^{h}(c)\left(q^{i}+k^{+}\right)-\sum_{y=1}^{S} \partial_{c_{y}} u^{h}(c) d_{y}^{i}-\lambda^{+, h, i} & =0 \quad \text { for } h \in H, i \in I \\
\partial_{c_{0}} u^{h}(c)\left(-q^{i}+k^{-}\right)+\sum_{y=1}^{S} \partial_{c_{y}} u^{h}(c) d_{y}^{i}-\lambda^{-, h, i} & =0 \quad \text { for } h \in H, i \in I \\
c_{0}-e_{0}^{h}+p \theta+\left(q+k^{+}\right) \vartheta^{+}-\left(q-k^{-}\right) \vartheta^{-} & =0 \quad \text { for } h \in H \\
c_{y}-e_{y}^{h}-a_{y} \theta-d_{y}\left(\vartheta^{+, h}-\vartheta^{-, h}\right) & =0 \quad \text { for } h \in H, s \in S \\
\vartheta^{+, h, i} & \geq 0 \quad \text { for } h \in H, i \in I \\
\vartheta^{-, h, i} & \geq 0 \quad \text { for } h \in H, i \in I \\
\lambda^{+, h, i} \vartheta^{+, h, i} & =0 \quad \text { for } h \in H, i \in I \\
\lambda^{-, h, i} \vartheta^{-, h, i} & =0 \quad \text { for } h \in H, i \in I \\
\lambda^{+, h, i} & \geq 0 \quad \text { for } h \in H, i \in I
\end{aligned}
$$




$$
\begin{array}{rlrl}
\lambda^{-, h, i} & \geq 0 & \text { for } h \in H, i \in I \\
\sum_{h \in H} \theta^{h, j} & =0 & & \text { for } j \in J \\
\sum_{h \in H}\left(\vartheta^{+, h, i}-\vartheta^{-, h, i}\right) & =0 & \text { for } i \in I
\end{array}
$$

Equations (1)-(11) are the first-order conditions for agent $h$. The last two equations (12) and (13) are the market-clearing conditions. The agents have to pay transaction fees whenever they trade a new security and so it will never be optimal for them both to buy and to sell short a new security at time $t=0$. Thus, $\bar{\vartheta}^{+, h, i} \cdot \bar{\vartheta}^{-, h, i}=0$ for all new assets $i \in I$.

In the presence of transaction fees on the financial markets, market clearing on these markets does not imply market clearing on the spot markets. The financial transactions "burn" real resources and so $\sum_{h \in H}\left(\bar{c}_{0}^{h}-e_{0}^{h}\right)<0$ whenever $\sum_{h \in H} \bar{\vartheta}^{+, h}>0$. Only in time period $t=1$ market clearing on the spot markets holds since there is no asset trading anymore in the final period. The following market-clearing condition holds at $t=0$ :

$$
\sum_{h \in H} e_{0}^{h}=\sum_{h \in H} \bar{c}_{0}^{h}+k^{+} \sum_{h \in H} \bar{\vartheta}^{+, h}+k^{-} \sum_{h \in H} \bar{\vartheta}^{-, h}
$$

It is important to notice that in equilibrium there might be an indeterminacy in the security prices. If the transaction fees $k^{+}$or $k^{-}$for an asset are too large in comparison to the benefit the agents can obtain from trading this security, the market for this asset will be closed resulting in an undetermined price. A continuum of asset prices supports the no-trade equilibrium. All equilibria are allocationally equivalent. Herings and Schmedders (1999) provide a detailed discussion on the existence of a continuum of equilibria and prove the following result.

Theorem 1 For a generic set of agents' endowments the economy $(\mathcal{E})$ has an equilibrium. The number of different equilibrium allocations is odd.

For other existence proofs of equilibria for models with transaction costs see Laitenberger (1991), Yamazaki (1991), and Préchac (1994).

\subsection{Entrepreneurial Market Maker}

We introduce a market maker into the finance economy. The model of this financial innovator is motivated by banks and exchanges that introduce new securities in order to obtain profits from charging investors transaction fees for trading the new assets. The financial innovator owns an 
exchange with the monopolistic right to introduce and intermediate new securities. She can also choose the transaction fees she charges agents trading on her exchange. All trades in the new securities must go through the exchange.

The market maker's technology for introducing and trading securities results in both fixed and variable transaction costs. The fixed costs of creating a new asset $i$ with payoff structure $d^{i}$ are denoted by $f^{i}=f^{i}\left(d^{i}\right)$, the variable costs of trading asset $i$ are denoted by $v^{i}=v^{i}\left(d^{i}\right)$. We make some assumptions on the cost functions to obtain independence of costs from the denomination of the payoff vector $d^{i}$.

Assumption: The transaction cost functions have the following properties:

1. $f^{i}(d) \geq 0, v^{i}(d) \geq 0 \quad \forall d \in \Re_{+}^{M}$

$d=0 \Rightarrow f^{i}(d)=v^{i}(d)=0$.

2. $f^{i}(\lambda d)=f^{i}(d) \quad \forall \lambda>0, d \in \Re_{+}^{M}$;

$v^{i}(\lambda d)=\lambda v^{i}(d) \quad \forall \lambda>0, d \in \Re_{+}^{M}$.

The first condition assumes all costs to be nonnegative and ensures that issuing an asset with $d=0$ is the same as not issuing a new security and not incurring any costs. The second assumption requires that a scaling of the asset payoffs does not affect the fixed cost of introducing the asset but results in an equivalent scaling of the variable transaction costs. This assumption is needed for the normalizations below, but it appears questionable for options.

The entrepreneur is restricted to introduce a finite number $I$ new securities. The market makers' profit function when she introduces $I$ assets with dividend payoffs $d$ to the economy charging agents transaction fees $k^{+, i}\left(k^{-, i}\right)$ for buying (selling) security $i$ equals

$$
P\left(d, k^{+}, k^{-}\right)=\sum_{i \in I}\left\{\left(k^{+, i}-v^{i}\right) \sum_{h \in H} \bar{\vartheta}^{+, h, i}+\left(k^{-, i}-v^{i}\right) \sum_{h \in H} \bar{\vartheta}^{-, h, i}-f^{i}\right\}
$$

The exchange owner's objective is to find securities and transaction fees that maximize her profits. In our computations we will frequently set $f^{i}=v^{i}=0$ so that profit maximization simplifies to revenue maximization. The entrepreneur only cares about period $t=0$ since there is no asset trading at $t=1$. Therefore, we do not need to specify her probability distribution for the states in the second period. 
Definition 2 A profit-maximizing equilibrium for the finance economy with a monopolistic market maker issuing I new securities is a decision triple $\left(d^{*},\left(k^{+}\right)^{*},\left(k^{-}\right)^{*}\right)$ such that there exists an equilibrium for the resulting finance economy $(\mathcal{E})$ such that for any equilibrium of any other choice triple $\left(d, k^{+}, k^{-}\right)$it holds that $P\left(d^{*},\left(k^{+}\right)^{*},\left(k^{-}\right)^{*}\right) \geq P\left(d, k^{+}, k^{-}\right)$.

At this point of the development we face two technical difficulties. First, the profit function $P\left(d, k^{+}, k^{-}\right)$is not well-defined if there are multiple equilibria in the finance economy. Given a market maker's decision $\left(d, k^{+}, k^{-}\right)$there may exist several equilibria resulting in different profits for the exchange. As a consequence the requirement of the definition might be satisfied for one equilibrium but maybe not for another one given the decision $\left(d^{*},\left(k^{+}\right)^{*},\left(k^{-}\right)^{*}\right)$. Unfortunately, at this point only very few restrictive conditions are known to ensure uniqueness in finance economies (see Hens et al. (1999) for a state-of-the-art description). In our computations a small change in the parameter values of the model always leads to a small change in the equilibrium quantities. So, although we cannot rule out multiple equilibria, it appears as if we compute and compare equilibria that lie in the same regular part of the equilibrium manifold. Therefore, we disregard the multiplicity issue for the remainder of this paper and assume that the profit function is welldefined. ${ }^{1}$ The second technical difficulty is of much bigger concern. Hara (1995) emphasizes an important feature of his (and our) model, namely that a market maker simultaneously choosing several assets may have an incentive to introduce assets such that the resulting security structure is arbitrarily close to redundancy. The supremum of the total commission revenues, over the choice set of proportional transaction fees and payoff structures of a fixed number of assets, cannot be achieved. The intuition for this phenomenon is straightforward. Consider a sequence of security payoffs approaching linear dependency. As the market span approaches a drop in rank the investors have the desire to hold unboundedly large long and short positions of the assets. If the market maker chooses a decreasing sequence of proportional commissions, the resulting total revenues in sequence of ensuing market equilibria may be increasing. The supremum, however, cannot be achieved, because in the limit the market span drops in rank and the assets' payoffs are redundant. Hara (1995) proves that this problem does not occur in his model if the number of innovated securities is at most 2. During computational exercises we have found many parameterized examples of our model with the same existence problem. Our computational analysis below focuses on a version of

\footnotetext{
${ }^{1}$ Hara (1995) shows that in his model with mean-variance utility functions and one riskless asset the revenues are unique even in the presence of multiple equilibria.
} 
the model for which we can show that the described existence problem cannot occur.

\subsection{Normalizations}

We characterize some properties of the model of a finance economy with a monopolistic market maker. These properties show how our model relates to the literature and also simplify our choice of parameter values for our computational analysis in the later sections.

Lemma 1 Let $\left(\left(c^{h}\right)_{h \in H},\left(\theta^{h}\right)_{h \in H},\left(\vartheta^{+, h}, \vartheta^{-, h}\right)_{h \in H},\left(p^{j}\right)_{j \in J},\left(q^{i}\right)_{i \in I}\right)$ be an equilibrium for the finance economy with the market maker's choices $\left(\left(d^{i}\right)_{i \in I},\left(k^{+, i}, k^{-, i}\right)_{i \in I}\right)$ resulting in a profit $P$. Then for the economy with the market maker's choices $\left(\left(\xi^{i} d^{i}\right)_{i \in I},\left(\xi^{i} k^{+, i}, \xi^{i} k^{-, i}\right)_{i \in I}\right)$, where $\xi^{i}>0 \quad \forall i \in I$, the process $\left(\left(c^{h}\right)_{h \in H},\left(\theta^{h}\right)_{h \in H},\left(\frac{1}{\xi^{i}} \vartheta^{+, h, i}, \frac{1}{\xi^{i}} \vartheta^{-, h, i}\right)_{h \in H},\left(p^{j}\right)_{i \in J},\left(\xi^{i} q^{i}\right)_{i \in I}\right)$ is an equilibrium and results in a market maker's profit of $P$.

By scaling the dividend processes and transaction fees of the innovated securities up or down the market maker cannot increase her profits. The agents can adjust their portfolios accordingly without changing their consumption allocations and transaction expenditures.

Lemma 2 Let $\left(\left(c^{h}\right)_{h \in H},\left(\theta^{h}\right)_{h \in H},\left(\vartheta^{+, h}, \vartheta^{-, h}\right)_{h \in H},\left(p^{j}\right)_{j \in J},\left(q^{i}\right)_{i \in I}\right)$ be an equilibrium for the economy with the market maker's choices $\left(\left(d^{i}\right)_{i \in I},\left(k^{+, i}, k^{-, i}\right)_{i \in I}\right)$ resulting in a profit $P$. Then for all $\hat{k}^{+, i}, \hat{k}^{-, i} \geq 0$ with $\hat{k}^{+, i}+\hat{k}^{-, i}=k^{+, i}+k^{-, i}$ there exist a unique price process $\left(\hat{q}^{i}\right)_{i \in I}$ so that $\left(\left(c^{h}\right)_{h \in H},\left(\theta^{h}\right)_{h \in H},\left(\vartheta^{+, h}, \vartheta^{-, h}\right)_{h \in H},\left(p^{j}\right)_{j \in J},\left(\hat{q}^{i}\right)_{i \in I}\right)$ is an equilibrium for the economy with the market maker's choices $\left(\left(d^{i}\right)_{i \in I},\left(\hat{k}^{+, i}, \hat{k}^{-, i}\right)_{i \in I}\right)$ resulting in a profit $P$.

Proof: Let $\hat{k}^{+, i}$ be such that $k^{+, i}+k^{-, i} \geq \hat{k}^{+, i} \geq 0$. Define $\hat{q}^{i}=q^{i}+\left(k^{+, i}-\hat{k}^{+, i}\right)$ and $\hat{k}^{-, i}=$ $k^{+, i}+k^{-, i}-\hat{k}^{+, i}$. Then $\hat{q}^{i}+\hat{k}^{+, i}=q^{i}+k^{+, i}$ and $\hat{q}^{i}-\hat{k}^{-, i}=\hat{q}^{i}-k^{+, i}-k^{-, i}+\hat{k}^{+, i}=q^{i}-k^{-, i}$. As long as $q^{i}+k^{+, i}$ and $q^{i}-k^{-, i}$ remain constant the equilibrium conditions (2)-(4) remain satisfied.

As long as the sum of the transaction fees for buying and selling remains constant, the asset prices for the new assets can be adjusted in such a fashion that all other variables in an equilibrium can stay unchanged for the process to remain an equilibrium and to result in the same profit for the market maker. Two special cases are of interest now. First, when $k^{-, i}=0$ for all $i \in I$ the transaction fee $k^{+, i}$ for buying is equivalent to the bid-ask spread in the model of Bisin (1998). Secondly, for simplicity we can restrict ourselves for the remainder of this paper to the case $k^{i} \equiv$ 
$k^{+, i}=k^{-i}$ for all $i \in I$, that is, the exchange owner charges identical fees for buying and selling the new securities (as in the model of Hara (1995)).

\section{Financial Innovation through an Option Exchange}

The computational analysis in the next few sections focuses on the monopolistic option introduction in finance economies. We examine two different motives of agents to trade the option despite the fact that they must pay transaction fees to the option exchange. The option introduction increases the asset span of the securities in the market. If agents have heterogeneous levels of risk aversion, then the option leads to increased risk-sharing opportunities. We examine economies with such agents in Section 4. When agents have identical risk aversion they still want to trade the option when they have heterogeneous beliefs about the states at time $t=1$. The option introduction gives them additional opportunities for portfolio re-balancing in the presence of disagreement about the probability of future economic shocks. Section 5 examines economies with agents that have heterogeneous beliefs.

\subsection{The Option Exchange}

For the computations in the remainder of this paper we need to focus on specific parameterizations of our model. For this reason we specialize the model of the entrepreneurial market maker. She is the owner of an options exchange having the right to introduce a single (European) call option with strike price $K$ on an already existing stock with dividends $a^{s}$ in the stochastic finance economy. The option has payoffs $d_{y}^{c}=\max \left\{0, a_{y}^{s}-K\right\}$ for $y=1, \ldots, S$. The market maker's objective function equals

$$
P(K, k)=\left(k-v^{c}\right) \sum_{h=1}^{H}\left(\bar{\vartheta}^{+, h, c}+\bar{\vartheta}^{-, h, c}\right)-f^{c} .
$$

Her decision problem is to determine the strike price $K^{*}$ of the option and the fee $k^{*}$ agents have to pay for trading the option on her exchange in order to maximize $P(K, k)$.

The assumption that the market maker introduces only a single option greatly reduces the number of decision variables for the entrepreneur. Instead of specifying an asset payoff for every possible state at $t=1$, the exchange owner only needs to specify a single number, namely the strike price. The market maker can only make a profit if the option payoffs are not spanned by the existing assets, because the agents can trade these assets without paying any transaction fees. 
The exchange owner must choose the strike price in such a fashion that the option payoff vector is independent of the payoff vectors of the existing assets. In a model with a riskless asset and the stock this requirement leads to a lower and upper bound on $K$, namely the smallest and largest payoff of the stock. Therefore, we can restrict our search for the optimal $K^{*}$ to a bounded interval. Also, the set of positive transaction fees resulting in nonzero trade is bounded. These observations make the problem of finding the profit-maximizing pair $\left(K^{*}, k^{*}\right)$ computationally feasible.

\subsubsection{Call vs. Put}

We compare the equilibria of two different economies. Both economies have identical established assets, a riskless security paying $a^{b} \equiv 1$ and a stock paying dividends $a^{s}$. In the first economy the option exchange introduces a call option with strike $K$, in the second economy it introduces a put option with strike $K$ and payoffs $d_{y}^{p}=\max \left\{0, K-a_{y}^{s}\right\}$ for $y=1, \ldots, S$. The following proposition shows how the (well-known) relationship between the two equilibria (the put-option equilibrium values of the variables are denoted by $\bar{c}^{h}$, etc.) implies that the market maker is indifferent between a call and a put introduction.

\section{Proposition 1 (Allocational Equivalence of Call and Put)}

The market maker is indifferent between the introduction of a call or a put option with strike price $K$ because of the following relationship between equilibria of the call-option economy and the put-option economy. Let $\left(\left(c^{h}\right),\left(\theta^{h, s}, \theta^{h, b}\right),\left(\vartheta^{+, h, c}, \vartheta^{-, h, c}\right),\left(p^{s}, p^{b}\right),\left(q^{c}\right)\right)$ be the equilibrium of the call-option economy at the transaction fee $k$. The put-option equilibrium for the same fee $k$ equals:

$$
\begin{aligned}
& \bar{c}^{h}=c^{h} \\
& \bar{\theta}^{h, s}=\theta^{h, s}+\left(\vartheta^{+, h, c}-\vartheta^{-, h, c}\right), \bar{\theta}^{h, b}=\theta^{h, b}-K\left(\vartheta^{+, h, c}-\vartheta^{-, h, c}\right), \\
& \bar{\vartheta}^{+, h, p}=\vartheta^{+, h, c}, \bar{\vartheta}^{-, h, p}=\vartheta^{-, h, c}, \\
& \bar{p}^{s}=p^{s}, \bar{p}^{b}=p^{b} \\
& \bar{q}^{p}=q^{c}-p^{s}+K p^{b} \text { (put-call parity). }
\end{aligned}
$$

Proof: Substituting the relationship $d^{c}=d^{p}+a^{s}-K \cdot a^{b}$ into the agents' budget equations (5) at time 1 yields

$$
\begin{aligned}
c_{y}^{h}-e_{y}^{h} & =a_{y}^{s} \theta^{h, s}+a_{y}^{b} \theta^{h, b}+d_{y}^{c}\left(\vartheta^{+, h, c}-\vartheta^{-, h, c}\right) \\
& =a_{y}^{s}\left(\theta^{h, s}+\vartheta^{+, h, c}-\vartheta^{-, h, c}\right)+a_{y}^{b}\left(\theta^{h, b}-K\left(\vartheta^{+, h, c}-\vartheta^{-, h, c}\right)\right)+d_{y}^{p}\left(\vartheta^{+, h, c}-\vartheta^{-, h, c}\right)
\end{aligned}
$$


The budget equations (4) at time 0 can be rewritten accordingly.

$$
\begin{aligned}
c_{0}^{h}-e_{0}^{h}= & p^{s} \theta^{h, s}+p^{b} \theta^{h, b}+q^{c}\left(\vartheta^{+, h, c}-\vartheta^{-, h, c}\right)+k\left(\vartheta^{+, h, c}+\vartheta^{-, h, c}\right) \\
= & p^{s}\left(\theta^{h, s}+\vartheta^{+, h, c}-\vartheta^{-, h, c}\right)+p^{b}\left(\theta^{h, b}-K\left(\vartheta^{+, h, c}-\vartheta^{-, h, c}\right)\right) \\
& +\left(q^{c}-p^{s}+K p^{b}\right)\left(\vartheta^{+, h, c}-\vartheta^{-, h, c}\right)+k\left(\vartheta^{+, h, c}+\vartheta^{-, h, c}\right)
\end{aligned}
$$

Using equations (1) we can transform (2) as follows.

$$
\begin{aligned}
0 & =\partial_{c_{0}} u^{h}(c)\left(q^{c}+k\right)-\sum_{y=1}^{S} \partial_{c_{y}} u^{h}(c) d_{y}^{c}-\lambda^{+, h, c} \\
& =\partial_{c_{0}} u^{h}(c)\left(q^{c}+k\right)-\sum_{y=1}^{S} \partial_{c_{y}} u^{h}(c)\left(d_{y}^{p}+a_{y}^{s}-K a_{y}^{b}\right)-\lambda^{+, h, c} \\
& =\partial_{c_{0}} u^{h}(c)\left(q^{c}-p^{s}+K p^{y}+k\right)-\sum_{y=1}^{S} \partial_{c_{y}} u^{h}(c) d_{y}^{p}-\lambda^{+, h, c}
\end{aligned}
$$

The same change can be made in equations (3). Defining $\bar{q}^{p}=q^{c}-p^{s}+K p^{b}, \bar{\theta}^{h, s}=\theta^{h, s}+\left(\vartheta^{+, h, c}-\right.$ $\left.\vartheta^{-, h, c}\right), \bar{\theta}^{h, b}=\theta^{h, b}-K\left(\vartheta^{+, h, c}-\vartheta^{-, h, c}\right), \bar{\vartheta}^{+, h, p}=\vartheta^{+, h, c}, \bar{\vartheta}^{-, h, p}=\vartheta^{-, h, c}, \bar{\lambda}^{+, h, p}=\lambda^{+, h, c}, \bar{\lambda}^{-, h, p}=$ $\lambda^{-, h, c}$, it becomes readily apparent that all equilibrium conditions (1)-(13) are satisfied for the put-option economy with identical consumption allocations, stock and bond prices. In particular, the individual holdings of the call option are identical to the agents' put-option positions. The total trading volume on the option exchange is the same in both economies resulting in identical profits for the market maker.

Proposition 1 has several implications. There is no loss of generality when we consider only a call-option introduction by the option exchange. We can always easily calculate the corresponding put-option equilibrium. The maximizing pair $\left(K^{*}, k^{*}\right)$ is identical for both options. The equilibrium prices for the established assets are unaffected by the option introduction, but the equilibrium trades are not.

Corollary 1 The maximum profits the exchange owner can receive by introducing a single call option with strike price $K$ on an existing stock with payoffs $a_{1}^{s}<a_{2}^{s}<\ldots<a_{S}^{s}$ has the following properties:

1. For $a_{S-1}^{s} \leq K<a_{S}^{s}$ the maximum profit $P^{*}\left(K, k^{*}\right)$ of the exchange is constant. 
2. If there is also a riskless asset in the economy paying one unit of the consumption good in every state in the second period, then for $a_{1}^{s}<K \leq a_{2}^{s}$ the maximum profit $P^{*}\left(K, k^{*}\right)$ of the exchange is constant.

Proof: For $a_{S-1}^{s} \leq K<a_{S}^{s}$ the option payoff equals $a_{y}^{s}-K$ in state $S$ and 0 in all other states. Changing $K$ within this interval amounts to multiplying $d^{o}$ by a positive factor. So, statement 1 is a direct consequence of Lemma 1. Proposition 1 implies that the proof for part 1 also shows the second part of the corollary.

This corollary implies that for finding the optimal pair $(K, k)$ we can restrict ourselves to values of $K$ such that $a_{2}^{s} \leq K \leq a_{S-1}^{s}$ (see also Detemple, Selden (1991, Remark 3.2)). For all the computations in the remainder of this paper we consider an economy with $H=2$ agents, $S=8$ states in period 1, and $J=2$ assets, a bond and a stock. The bond is a riskless asset paying one unit of the consumption good in each of the eight states in the second period. The bond is in zero net supply and no agent is endowed with it. The stock is a risky security with state-dependent payoffs. The stock is in unit net supply and the initial holdings are $\theta_{-1}^{1, s t}=\theta_{-1}^{2, s t}=0.5$. Both agents have zero initial endowment. (Note that this economy is equivalent to one with a stock in zero net supply and zero initial holdings and agents having identical labor endowments equal to half the stock's dividends; thus, this economy fits into the framework of our model.) The technology of the market maker allows her to introduce a single option on the stock at zero cost, that is, $f^{c}=v^{c}=0$. The entrepreneur's profit function equals

$$
P(K, k)=k \cdot \sum_{h \in H}\left(\bar{\vartheta}^{+, h, c}+\bar{\vartheta}^{-, h, c}\right) .
$$

Note, that for this parameterization of our model a revenue-maximizing equilibrium always exists. The optimal value $K^{*}$ must lie in the interval $\left[a_{2}^{s}, a_{S-1}^{s}\right]$ and for all values of $K$ in this interval the market span does not approach a redundancy.

\section{Homogeneous Beliefs}

Both agents have identical von-Neumann-Morgenstern CRRA utility functions with identical uniform beliefs. That is, agent $h$ 's utility function equals

$$
u^{h}(c)=\frac{c_{0}^{1-\gamma^{h}}}{1-\gamma^{h}}+\sum_{y=1}^{8} \frac{1}{8} \frac{c_{y}^{1-\gamma^{h}}}{1-\gamma^{h}},
$$


with $0<\gamma_{h} \neq 1$ being the coefficient of relative risk aversion (and log-utility for the case $\gamma^{h}=1$ ).

In a first exercise we demonstrate how we can find the optimal pair $\left(K^{*}, k^{*}\right)$ yielding the maximum revenue for the option exchange.

\subsection{Optimal Strike Price and Transaction Fee}

Let the stock's payoffs equal $a_{0}^{s}=1, a_{1}^{s}=(0.5,0.65,0.8,0.95,1.05,1.2,1.35,1.5)$. The coefficients of relative risk-aversion are $\gamma^{1}=1$ and $\gamma^{2}=5$, respectively. In a first step we fix the strike price of the option at $K=0.749$ and compute equilibria as a function of $k$.

\section{[FIGURES 1 AND 2 ABOUT HERE]}

Figure 1 displays the equilibrium option trade of agent 1 as a function of the proportional transaction fee $k$. As expected the higher the transaction fees the less the agents trade the option. The relationship appears to be almost linear until the fee has become so large that the agents no longer want to trade the option. As a consequence the revenue function for the option exchange has a concave, parabolic shape (until the option market closes) with a unique local and thus global maximum, see Figure 2. The maximum revenues are attained at a fee of $3.137 \cdot 10^{-3}$ and equal $4.6419 \cdot 10^{-4}$. Agent 1 holds 0.073985 units of the option at those fees. The findings of this example are typical and we have found them for a wide range of stock payoffs, strike prices for the option, and number $S$ of states in the second period.

Computational Result 1 In the two-period model with two agents the option trades decrease almost linearly in the transaction fee $k$ resulting in a concave parabolic shape of the revenue function until the option market closes and revenues are zero.

Figure 3 illustrates our first computational result for four different levels of risk aversion for agent 2.

\section{[FIGURE 3 HERE]}

In the next step we now vary the strike price $K$ and determine $k^{*}(K)$ and the corresponding revenues in order to find the maximizing pair $\left(K^{*}, k^{*}\right)$. In our current example the relevant values for the strike price are $0.5<K<1.5$ since the option is redundant for any other strike prices. Figure 4 shows the concentration of the revenue function as a function of $K$, that is, the maximum 
revenues the option exchange can achieve with an option having strike price $K$. As predicted by Corollary 1 , the function is constant for $0.5<K \leq 0.65$ and $1.35 \leq K<1.5$.

\section{[FIGURE 4 ABOUT HERE]}

We can distinguish $S-1=7$ intervals in each of which the revenue function appears to be differentiable. The boundaries of these intervals are given by the various payoffs of the stock, and the intervals correspond to the number of states with a nonzero option payoff. For example, for $0.5<K \leq 0.65$ the option has a nonzero payoff in 7 of 8 states, for $0.65<K \leq 0.8$ in 6 of 8 states, and so on. Whenever $K$ equals one of the payoffs, the revenue function exhibits a non-differentiability but remains continuous. The revenue function exhibits two local optima. Comparing the revenue values at those two strike prices reveals that the unique maximum is attained at $K^{*}=0.749$ and $k^{*}=3.137 \cdot 10^{-3}$.

Figures 5 and 6 allow us to take a separate look at the two factors determining the market maker's revenues as a function of the strike price $K$, respectively, the option trade of the agents and the maximizing transaction fee. We see that the large values of the revenue function are obtained for relatively large transaction fees but comparatively low transaction volume. Moreover, it also becomes obvious, that the choice of $k^{*}$ depends on the strike price $K$, that is, the asset payoffs. A sole maximization of transaction volume (as in Duffie and Jackson (1989)) is inappropriate for our model, since it leads to the previously mentioned redundancy problems. These observations emphasize that a joint examination of both the trading volume and the transaction fees is important in order to determine the best decision for the exchange owner.

\section{[FIGURES 5 AND 6 ABOUT HERE]}

Figure 7 shows the option price as a function of the strike price. The larger the strike price the smaller the expected payoff of the option resulting in a lower option price. We do not show the graphs of the prices for the other two assets, there is very little variation in those prices.

[FIGURE 7 ABOUT HERE] 
Finally we investigate the welfare impact of the option introduction for the two agents in the economy. In the incomplete markets model the agents disagree on the state prices and so the concepts of equivalent variation and compensating variation are not well-defined. Therefore we define another measure for wealth comparisons as follows. The welfare change due to the option introduction equals the fraction of additional first-period consumption in the economy without the option exchange that would make the agent as well off as he is in the economy with the option exchange. The formulas for this welfare measure for all the utility functions that we use in this paper are given in Appendix C. Figures 8 and 9 show the welfare change for the agents as functions of the strike price. The less risk-averse agent 1 experiences a welfare loss for all possible strike prices of the option, the more risk-averse agent 2 always obtains a welfare gain from the option introduction.

\section{[FIGURES 8 AND 9 ABOUT HERE]}

Recall our definition of the concentration of the revenue function as a function of $K$ as the function of the maximum revenues the option exchange can achieve with an option having strike price $K$.

Computational Result 2 The two-agent model with CRRA utility functions exhibits the following properties:

1. The concentration of the revenue function is continuous in $K$. For $a_{y}^{s}<K<a_{y+1}^{s}, y=$ $2, \ldots, S-2$, the function is differentiable and concave. Typically there exist a unique global maximum $K^{*}$.

2. The large values of the concentration of the revenue function are typically attained for relatively large transaction fees and relatively small trading volumes.

3. The concentration of the call-option price function $q^{c}$ is a decreasing function of $K$.

\subsection{Comparative Statics: Varying Risk-Aversion}

We continue with comparative statics exercises for the coefficients of relative risk aversion for the two agents. Table 1 shows the profit maximizing pairs $\left(K^{*}, k^{*}\right)$ for various pairs $\left(\gamma^{1}, \gamma^{2}\right)$ and the resulting profit $P^{*}\left(K^{*}, k^{*}\right)$. It also displays the agents' trades in economies with and without the option exchange. All asset prices in those two economies are depicted in Table 2. That table also 
shows the welfare effects of the option introduction.

[TABLES 1 AND 2 ABOUT HERE]

Computational Result 3 The call option introduction in the two-agent model with CRRA utility functions has the following impact:

1. The more risk-averse agent always sells the call option short, sells part of his stock holding, and buys the bond.

2. The call option introduction always leads to a decrease in the trading volume for the bond and the stock.

3. The call option introduction always leads to a decrease in the prices of the bond and the stock.

For fixed $\gamma^{1}$ and $\gamma^{1}<\gamma^{2}$ we observe:

4. The maximum revenues for the market maker increase as $\gamma^{2}$ increases.

5. The optimal strike price $K^{*}$ decreases and the optimal fee $k^{*}$ increases as $\gamma^{2}$ increases.

6. The welfare gain for agent 2 increases and the welfare gain for agent 1 decreases as $\gamma^{2}$ increases. Unless $\gamma^{2}$ and $\gamma^{1}$ are relatively close, the less risk-averse agent 1 has a welfare loss and the more risk-averse agent 2 has a welfare gain.

In an economy without the option exchange the two agents can only trade the bond and the stock in order to achieve some risk-sharing. Their trade is always of the same nature. The less risk-averse agent 1 sells some insurance in form of the bond to the more risk-averse agent 2 who in turn sells part of his stock holdings to the less risk-averse agent. The less risk-averse agent takes on more of the risk and demands a payment for doing so. For example, in the case $\gamma^{1}=1$ and $\gamma^{2}=5$ the asset trades of the first agent are $\theta^{1, b}=-0.270999$ and $\theta^{1, s t}=0.311799$ at prices $p^{b}=1.42271$ and $p^{s}=1.13128$. As a consequence the less risk-averse agent has a positive payoff (0.032821) from these trades at $t=0$ and at the same time a positive expected payoff $(0.040800)$ at time $T=1$. These payoffs are the reward for taking on more risk, or from the perspective of the more risk-averse agent, these are his payments for buying some insurance. As soon as the 
option exchange opens and offers a third asset the opportunities for risk-sharing increase. The more risk-averse agent is no longer forced to buy insurance only through buying the bond and selling a large portion of his stock holdings. Instead, compared to the no-option economy, he buys less of the bond, sells less of the stock, and now sells the call option. Short-selling the call option allows the more risk-averse agent to transfer wealth more easily from the high-dividend states to the low-dividend states. In equilibrium the less risk-averse agent is no longer able to extract as much of an insurance premium from the risk-averse agent as in the no-option economy. The asset trade $\left(\theta^{1, b}, \theta^{1, s t}, \vartheta^{+, 1, o}\right)=(-0.243463,0.263164,0.073985)$ generates net payoffs of 0.032144 and expected 0.021880 in periods 0 and 1 , respectively, for the less risk-averse agent, which is less than the corresponding payoffs in the no-option economy. The reduction in these payments has a larger impact on the less risk-averse agent's welfare than the increased risk-sharing opportunities due to the new security. Therefore, the option introduction hurts the less risk-averse agent and benefits the risk-averse agent. Only when the risk attitudes of the agents are very similar both agents gain from the option introduction. In this case the increased risk-sharing opportunities outweigh the effect of insurance selling, because in the no-option economy this effect was already very small.

\subsection{Comparative Statics: Varying Stock Dividend Risk}

We analyze the impact of the variance of stock dividends on the behavior of the finance economy. We rerun all experiments from the previous subsection for two other specifications of stock dividends, namely for dividends with lower variance, that is,

$$
a_{0}^{s}=1, a_{1}^{s}=(0.7,0.8,0.9,0.95,1.05,1.1,1.2,1.3),
$$

and dividends with higher variance, that is,

$$
a_{0}^{s}=1, a_{1}^{s}=(0.3,0.5,0.7,0.9,1.1,1.3,1.5,1.7)
$$

The dividend variance of the first stock equals 0.035625 , that of the second stock 0.21 . For comparison, the stock dividends in the previous examples had a variance of 0.10375 .

\section{[TABLES 3 AND 4 ABOUT HERE]}

Tables 3 and 4 give the corresponding information to Tables 1 and 2. Table 3 shows the profit

maximizing pairs $\left(K^{*}, k^{*}\right)$ for various pairs $\left(\gamma^{1}, \gamma^{2}\right)$, the resulting profit for the market maker, and 
the agents' trades in economies with and without the option exchange. All asset prices in those two economies are depicted in Table 4, as are the welfare effects of the option introduction.

Computational Result 4 As the variance of the stock payoffs increases,

1. so does the proportional transaction fee the exchange owner charges;

2. so does the transaction volume of the option;

3. so do the revenues of the exchange owner;

4. so do the agents' welfare changes due to the option introduction;

5. so do the prices of the bond and the stock (in both the economy with and the economy without the option).

\section{$5 \quad$ Heterogeneous Beliefs}

The stock payoffs are the same as in Section 4.1, that is, $a_{0}^{s}=1, a_{1}^{s}=(0.5,0.65,0.8,0.95,1.05,1.2,1.35,1.5)$. The beliefs of the agents are always chosen such that the expected payoff of the stock equals 1 for both agents. However, the agents have different risk assessments of the stock's payoffs. We consider 6 different belief structures.

$$
\begin{array}{lll}
\Pi(1) & \pi^{1}=(0.1,0.1,0.15,0.15,0.15,0.15,0.1,0.1), & \pi^{2} \equiv 0.125, \\
\Pi(2) & \pi^{1}=(0.1,0.125,0.125,0.15,0.15,0.125,0.125,0.1), & \pi^{2} \equiv 0.125, \\
\Pi(3) & \pi^{1}=(0.15,0.125,0.125,0.1,0.1,0.125,0.125,0.15), & \pi^{2} \equiv 0.125, \\
\Pi(4) & \pi^{1}=(0.15,0.15,0.1,0.1,0.1,0.1,0.15,0.15), & \pi^{2} \equiv 0.125, \\
\hline \Pi(5) & \pi^{1}=(0.2,0.1,0.1,0.1,0.1,0.1,0.1,0.2), & \\
& \pi^{2}=(0.2,0.225,0.05,0.025,0.025,0.05,0.225,0.2), & \\
\Pi(6) & \pi^{1}=(0.2,0.1,0.05,0.15,0.15,0.05,0.1,0.2), & \\
& \pi^{2}=(0.2,0.2,0.05,0.05,0.05,0.05,0.2,0.2) . &
\end{array}
$$

For belief structures $\Pi(1)$ and $\Pi(2)(\Pi(3)$ and $\Pi(4))$ the first agent assesses a lower (higher) risk to the stock payoffs than the second agent who has always uniform beliefs. For belief structures $\Pi(5)$ and $\Pi(6)$ both agents consider the stock dividends more risky than with the other 4 beliefs. In both cases the first agent assesses a lower risk to the stock payoffs. 


\section{Case 1: Constant Relative Risk Aversion}

Both agents have log-utility with heterogeneous beliefs. Agent $h$ 's utility function equals

$$
u^{h}(c)=\ln \left(c_{0}\right)+\sum_{y=1}^{8} \pi_{y}^{h} \ln \left(c_{y}\right)
$$

\section{Case 2: Linear-Quadratic Utilities}

Both agents have linear-quadratic utility functions of the form

$$
u^{h}(c)=c_{0}-\frac{1}{2} b\left(c_{0}\right)^{2}+\sum_{y=1}^{8} \pi_{y}^{h}\left(c_{y}-\frac{1}{2} b\left(c_{y}\right)^{2}\right)
$$

with $b>0$.

\section{Case 3: Constant Absolute Risk Aversion}

Both agents have CARA utility functions of the form

$$
u^{h}(c)=-e^{-a c_{0}}-\sum_{y=1}^{8} \pi_{y}^{h} e^{-a c_{y}}
$$

where $a$ is the coefficient of absolute risk aversion for both agents.

\subsection{Revenue-Maximizing Equilibria}

The revenue-maximizing equilibria for the economies in the three cases are structurally very similar. Therefore we display only the results for linear-quadratic utilities (Case 2) with $b=\frac{2}{3}$.

\section{[TABLES 5 AND 6 ABOUT HERE]}

Tables 5 and 6 give the corresponding information to Tables 1 and 2. Table 5 shows the profit maximizing pairs $\left(K^{*}, k^{*}\right)$ for the six belief structures and the resulting profit as well as the agents' trades in economies with and without the option exchange. All asset prices in the two economies

are depicted in Table 6 , as are the welfare effects of the option introduction. Note that the bond price in the economy without the option is always 1 .

Computational Result 5 We observe the following properties of the revenue-maximizing equilibria.

1. The agent with the lower risk assessment of the stock dividends always buys a portion of the stock and sells short both the bond and the option. 
2. The call option introduction leads to a significant increase in the transaction volume of the bond and the stock.

3. The call option introduction always leads to a decrease of the bond and stock price.

4. The call option introduction improves the welfare for both agents.

The beliefs of the agents are such that the agents have the same expected value of 1 for the stock dividends and have only fairly small belief differences of the dividend variance. As a result there is only very little trading in the economy without the call option. The agent with the higher risk assessment for the stock sells a small part of his stock and buys a small portion of the bond.

The situation changes considerably in the economy with the option exchange. The agent with the high risk assessment sells a large part of his stock holding (in the extreme cases 5 and 6 he even sells the stock short) and buys large portions of the bond and the call option. The long bond holding offers the agent some insurance against the negative outcomes that he gives a higher probability than the low-risk-assessment agent does. The long call position promises higher payoffs in the high dividend states that the agent again believes to be more likely than the low risk assessment agent does. Both types of agents always experience a welfare gain through the option introduction.

The revenue-maximizing equilibria for economies with agents having both log-utility or both CARA utility show the identical pattern as the presented equilibria for linear-quadratic utility functions. All statements of Computational Result 5 are also valid for economies with agents having these utility functions. The tables corresponding to Tables 5-6 can be obtained from the author upon request.

\subsection{The Detemple-Selden Conditions}

In all examples we have computed so far the asset prices for the bond and the stock always decrease when the call option is introduced. This observation is in stark contrast to the result for the model of a mean-variance economy examined by Detemple and Selden (1991, Section 4.1). Their model coincides with the linear-quadratic economy of this section except that agents have no first-period consumption. Detemple and Selden (1991) show that - under the restriction that the agents agree on the expected stock payoff, the expected option payoff, the variance of the option payoff, and the covariance between the stock and option payoffs - the option introduction always leads to an increase of the stock price. 
Detemple and Selden (1991) give the following explanation of the agents' behavior. They argue that investors with a high risk assessment have a relative preference for a portfolio paying off for large values of the stock dividends. To obtain such a portfolio such agents sell the stock and buy the call option. These agents view the stock and the option as substitutes. Further Detemple and Selden (1991) claim that the two assets are complementary for the agents with a low risk assessment resulting in buying more of the stock and short-selling the call option. Detemple and Selden (1991) further state that on an aggregate level the call option complements the stock because the second type of investor with a low risk assessment has a stronger reaction to the market changing due to the option introduction. They finally conclude that the call-option introduction makes the stock more valuable and thus its price increases. It is apparent from our computational results that this last conclusion does not hold in our model. The price of both the bond and the stock always decreases when the call option is introduced. It appears that while the intuition regarding the trading patterns is correct the conclusion about their impact on asset prices depends critically on the payoff restrictions of Detemple and Selden (1991).

Sufficient conditions for these restrictions to be satisfied in our model are that the option pays off in only one state and the agents agree about the probability of that state. So, for example, an economy with beliefs $\Pi(6)$ satisfies the restrictions. Figure 10 shows the difference between the stock price in an economy with a call option having strike price $K$ and the stock price in the economy without the option. Only for $K \leq 0.662$ and $K \geq 1.338$ is this difference barely positive. As Figure 11 shows, options with these strike prices barely generate any revenue for the option exchange.

\section{[FIGURES 10 AND 11 ABOUT HERE]}

Of course, the comparison for the economy with beliefs $\Pi(6)$ is not fair, since for most values of $K$, and in particular the ones near the center of the interval, the payoff restrictions of Detemple and Selden (1991) are not satisfied. In order to perform a better comparison we create a new set of beliefs $\Pi(7)$ as follows. The second agent believes that every state in the second period has the same probability 0.125 . We define the probabilities of the first agent to be the optimal solution of a linear programming problem. Given a strike price $K=1$ the linear constraints are the restrictions of Detemple and Selden (1991) and that the expected stock payoff equals 1 . In 
order to rule out negative consumption in any state of the world we also require that every probability must be at least 0.08 . The objective of the LP is to maximize the second moment of the stock dividends under the beliefs of the first agent. One of the optimal solutions to this LP is $\pi(1)=(0.179,0.08,0.08,0.08,0.23,0.125,0.08,0.146)$ resulting in $\operatorname{Var}\left(a^{s}, \pi(1)\right)=0.109825$. Under the uniform beliefs $\pi(2)$ the variance of the stock dividends equals 0.10375 .

[FIGURES 12, 13, 14 ABOUT HERE]

Figure 12 shows the difference of the stock prices in the economy with the option and the nooption model. For $0.981 \leq K \leq 1.017$ and $1.136 \leq K \leq 1.167$ the stock price increases through the option introduction. The maximal relative price increase of $5.680 \cdot 10^{-5}$ is caused by an option with strike price $K=0.999$. For most strike prices, though, the option introduction leads to a decrease of the stock price that is much larger than the largest increase. Figure 13 shows the revenues of the option exchange. All options with a strike price $0.5<K \leq 0.65$ lead to the maximum revenues of $7.108 \cdot 10^{-3}$ and a relative decrease of the stock price by $7.1 \cdot 10^{-3}$. At strike prices where the option introduction leads to an increase of the stock price there is barely any trading of the securities, see Figure 14.

The results of this last example are not accidental; in all of a dozen examples with beliefs satisfying the Detemple-Selden conditions and for various quadratic utility functions the stock price increase is always very small and confined to a small set of strike prices. Moreover, the options with such strike prices generate little revenue for the market maker and result in relatively small trading volume in all markets. In summary, although based on our computations we are not in the position to make general statements about the Detemple-Selden conditions, we conjecture that the strike prices that satisfy the restrictions lead to an asset span that allows only very little risk-sharing for the agents based on their heterogeneous beliefs. A revenue-maximizing option exchange has no desire to introduce options with such strike prices. Instead it will introduce options that lead to a substantial decrease in the stock price.

\subsection{Agent Heterogeneity}

Although we need to be careful when comparing the computational results for heterogeneous-beliefs model with those of the heterogeneous-risk-aversion model, it seems evident that the exchange 
owner can make more money when the agents have (modest) beliefs differences than when they have (reasonably) different levels of risk aversion. Comparing the revenue-maximizing equilibria for the computed examples of the two models we see that the option trading volume is roughly an order of magnitude higher in the heterogeneous-beliefs model. The maximizing fees are of the same order of magnitude resulting in much higher revenues for the market maker. We further observe different trading patterns in the two models depending on whether agent heterogeneity appears in the form of different levels of risk aversion or in the form of different risk beliefs for the stock's payoffs. In the model with homogeneous beliefs and heterogeneous levels of relative risk aversion the more risk-averse agent always sells both the stock and the (call) option in order to buy the bond; in the heterogeneous-beliefs model the agent with the higher risk assessment sells the stock to buy both the bond and the option. These different behaviors highlight the differences between the two forms of heterogeneous risk attitudes. The agent with higher relative risk aversion sells the option short (and buys the bond with the proceeds) in order to transfer wealth from the high-dividend states into the low-dividend states. The agent with the belief of a higher dividend risk buys the option in order to receive an additional payoff in the high-dividend states that he believes to be more likely than his counterpart. To summarize, the way in which agents' heterogeneous risk attitudes are modeled matters.

\subsubsection{Strike Price vs. Stock Dividends}

Conventional wisdom states that the strike price of a successful option will be close or even equal to the price of the underlying security at the time of the issue of the option. In the context of our model it is not sensible to examine this convention as the option is truly an option only on the stock's dividend, since there is no stock trading and so no stock price at time $t=1$. Also, the stock price is driven by the risk attitudes of the agents. In the examples in Section 4 the stock price is frequently above the highest possible dividend for the subsequent period (resulting in a negative return). For such levels of the strike price the option would be redundant. However an interesting question is how close the strike price of the revenue-maximizing option is to the expected stock payoff, since the option is a derivative on the stock dividends. The expected stock payoff in all the examples in this paper equals 1.

Tables 2 and 4 show for the heterogeneous-risk-aversion economies that the strike price of the revenue-maximizing option is always smaller than the expected stock payoff and decreases as the 
coefficient of risk aversion of the more risk-averse agent increases, see Computational Result 3.5. When the differences between the risk coefficients become significantly large the strike price is more than $25 \%$ below the expected stock payoff. As the second agent becomes more risk averse his fear of the worst stock dividend states increases. The smaller the strike price of the option the better the more risk-averse agent can use the option to insure against those very negative outcomes.

The situation is quite different for the heterogeneous-beliefs economies. Table 7 shows for some representative economies that for all three utility functions under consideration in this section the strike price of the option appears to be much closer to the expected stock payoff than in the heterogeneous-risk-aversion examples. The differences are particularly small for economies with CARA utility functions (for which they are remarkably stable for moderate changes of the riskaversion coefficient).

\section{[TABLE 7 ABOUT HERE]}

\section{Conclusion}

In this paper we have analyzed endogenous asset innovation by an entrepreneurial exchange owner in a partial equilibrium model of incomplete security markets with financial transaction fees. A monopolistic market maker has the technology to introduce new securities into the economy and charge investors transaction fees if they trade on the exchange. The market maker's objective is to choose the security and transaction fee that maximize profits when opening the exchange.

We have computed the effects of asset innovation for the case of an option exchange introducing an option on a stock index and have presented a detailed analysis of a variety of examples. We examined two motives for agents to trade securities. First, to achieve risk-sharing when agents have homogeneous beliefs but heterogeneous levels of risk aversion. Secondly, to do portfolio rebalancing when agents have identical levels of risk aversion but heterogeneous beliefs. The most striking result of our computations is that the introduction of the profit-maximizing option leads always to a decrease of the prices of the established securities. Typically small heterogeneity of beliefs leads to substantially more trading volume of the option than reasonable differences among levels of risk aversion.

This paper obviously presents only a first step in the computational analysis of financial innovation in general equilibrium models with incomplete markets. Many interesting issues remain to 
be examined, we just mention two immediate extensions of the present analysis. We might want to take nonzero transaction fees for established assets into account. Such a model would allow us to examine the value of derivatives such as options as a tool to reduce total transaction fees for achieving desired portfolio payoffs. Another topic of importance would be to examine financial innovation in multi-period models. Multiple periods would allow agents to rebalance their portfolios by retrading securities. We might expect many new phenomena to appear in such models. 


\section{Appendix}

In the first section of the Appendix we describe the algorithms used for our computations. The second section provides running times and numerical errors for some of the computational examples. Section $\mathrm{C}$ defines the wealth measure we use for all welfare comparisons.

\section{A Description of the Computations}

Computing a profit-maximizing decision $\left(K^{*}, k^{*}\right)$ for the option exchange is done in three steps. At first the strike price $K$ is fixed, and for some very small and evidently suboptimal value of $k$ an equilibrium of the finance economy is computed. In the second step, the optimal value $k^{*}$ for given $K$ is determined. Finally, the first two steps are repeated over a fine grid of points in the interval of possibly optimal strike prices in order to determine the value for $K^{*}$.

\section{Step 1: Computing an Equilibrium for the Finance Economy}

Computing an equilibrium for the finance economy requires solving the system of equations and inequalities (1) - (13). Using a variable transformation we eliminate the inequalities (6),(7),(10), and (11) in order to obtain a standard system of nonlinear equations (see (Garcia and Zangwill (1981)).

We introduce new variables $\alpha^{+, h, i} \in \mathbb{R}$ and $\alpha^{-, h, i} \in \mathbb{R}$ for all $h \in H$ and $i \in I$. Let $\kappa \geq 2$ be some positive natural number. Next define

$$
\begin{aligned}
\lambda^{+, h, i} & =\left(\max \left\{0, \alpha^{+, h, i}\right\}\right)^{\kappa} \\
\vartheta^{+, h, i} & =\left(\max \left\{0,-\alpha^{+, h, i}\right\}\right)^{\kappa} .
\end{aligned}
$$

Corresponding definitions apply for $\lambda^{-, h, i}$ and $\vartheta^{-, h, i}$. We substitute these expressions into the system (1) - (13). The nonnegativity constraints on the portfolio variables and Lagrange multipliers are satisfied simply by definition. In addition the complementary-slackness conditions (8) and (9) are satisfied immediately. Therefore, we can eliminate these constraints.

The remaining equations are solved via a homotopy approach. We define a homotopy parameter

$\eta \in[0,1]$ and starting prices $\hat{p}^{j}$ for all $j \in J$ and $\hat{q}^{i}$ for all $i \in I$. The homotopy equations are as 
follows:

$$
\begin{aligned}
& (1-\eta) \theta^{h, j}+\eta\left(\partial_{c_{0}} u^{h}(c) p^{i}-\sum_{y=1}^{S} \partial_{c_{y}} u^{h}(c) a_{y}^{i}\right)=0 \quad \text { for } h \in H, j \in J \\
& (1-\eta)\left(\max \left\{0,-\alpha^{+, h, i}\right\}\right)^{\kappa}+ \\
& \eta\left(\partial_{c_{0}} u^{h}(c)\left(q^{j}+k^{+}\right)-\sum_{y=1}^{S} \partial_{c_{y}} u^{h}(c) d_{y}^{j}\right)-\left(\max \left\{0, \alpha^{+, h, i}\right\}\right)^{\kappa}=0 \quad \text { for } h \in H, i \in I \\
& (1-\eta)\left(\max \left\{0,-\alpha^{-, h, i}\right\}\right)^{\kappa}+ \\
& \eta\left(\partial_{c_{0}} u^{h}(c)\left(-q^{j}+k^{-}\right)+\sum_{y=1}^{S} \partial_{c_{y}} u^{h}(c) d_{y}^{j}\right)-\left(\max \left\{0, \alpha^{-, h, i}\right\}\right)^{\kappa}=0 \quad \text { for } h \in H, i \in I \\
& c_{0}-e_{0}^{h}+p \theta+\left(q+k^{+}\right)\left(\max \left\{0,-\alpha^{+, h}\right\}\right)^{\kappa}-\left(q-k^{-}\right)\left(\max \left\{0,-\alpha^{-, h}\right\}\right)^{\kappa}=0 \quad \text { for } h \in H \\
& c_{y}-e_{y}^{h}-a_{y} \theta-d_{y}\left(\left(\max \left\{0,-\alpha^{+, h}\right\}\right)^{\kappa}-\left(\max \left\{0,-\alpha^{-, h}\right\}\right)^{\kappa}\right)=0 \quad \text { for } h \in H, s \in S \\
& \sum_{h \in H} \theta^{h, j}-(1-\eta)\left(p^{j}-\hat{p}^{j}\right)=0 \quad \text { for } j \in J \\
& \sum_{h \in H}\left(\left(\max \left\{0,-\alpha^{+, h, i}\right\}\right)^{\kappa}-\left(\max \left\{0,-\alpha^{-, h, i}\right\}\right)^{\kappa}\right)-(1-\eta)\left(q^{i}-\hat{q}^{i}\right)=0 \quad \text { for } i \in I
\end{aligned}
$$

The unique starting point at $\eta=0$ is given by $p=\hat{p}, q=\hat{q}, \theta^{h}=0, \alpha^{+, h}=\alpha^{-, h}=0, c^{h}=e^{h}$ for all $h \in H$. The entire system consists of $\mathrm{HJ}+2 \mathrm{HI}+\mathrm{H}(\mathrm{S}+1)+\mathrm{J}+\mathrm{I}$ equations in the unknowns $\eta$ and $p^{j}, q^{i}, \theta^{h, j}, \lambda^{+, h, i}, \lambda^{-, h, i}, c_{y}^{h}$ for $j \in J, i \in I, h \in H$, and $y \in Y$.

The implementation of the algorithm on a 400MHz-Pentium computer uses the software package HOMPACK77, a suite of Fortran 77 subroutines for solving nonlinear systems of equations using homotopy methods (Watson et al. (1987)). In order to reduce the number of equations to be solved we substitute the defining equations for the consumption variables into the remaining first-order conditions. For the example in Section 4.1 we then need to solve a system with 11 equations and variables. In addition to these equations we need to provide the software with the Jacobian of the left-hand side, which is approximated through a one-sided difference formula. Once the homotopy has found a solution to the equations, we use this solution as a starting point for HYBRD, a a suite of Fortran subroutines for solving nonlinear systems of equations using Powell's hybrid method. This Newton solver allows us to reduce the computational error very quickly.

\section{Step 2: Finding $\mathbf{k}^{*}$}

Once we have found an equilibrium for a very small $k=k_{0}$ that will be smaller than the 
optimal $k^{*}$ we increase $k$ until we find $k^{*}$. Setting $\eta=1$ in the homotopy of step 1 , we define a new homotopy by defining the transaction fee to be

$$
k=k_{0}(1+L * \nu)
$$

where $L$ is some large positive number and $\nu$ is the new homotopy parameter. Otherwise we use the same system as in step 1 with $\eta=1$. The solution of the first step is the starting point for the new homotopy when $\nu=0$. The number $L$ is chosen sufficiently large, so that the maximum value for $P(K, k)$ will be attained for a value of $\nu<1$.

Along the homotopy path we keep track of the value of $P(K, k)$. At first, due to the choice for $k_{0}$, the value of $P$ will increase along the path. As many computations have shown, the function $P$ has a unique local and thus global maximum as a function of $k$, see Computational Result 1. Therefore, as soon as the value for $P$ starts to decrease, we have found a rough approximate value $\tilde{k}$ for the maximizer $k^{*}$. The homotopy terminates. Next we start a search for the maximizer $k^{*}$ using a modified version of the bracketing method, see Judd (1998). We compute the equilibria and corresponding profits $P$ using the Newton solver at three values for $k$, namely $(1-\mu) \tilde{k}, \tilde{k}$, and $(1+\mu) \tilde{k}$, where $\mu$ is some small positive number. Next we calculate $P$ for $(1-\mu / 2) \tilde{k}$ and $(1+\mu / 2) \tilde{k}$ and update the interval in which the optimum has to lie. This procedure continues until the relative difference between the lower and upper bound of the interval is less than some given value $\epsilon$.

\section{Step 3: Finding $\left(\mathbf{K}^{*}, \mathbf{k}^{*}\right)$}

The first two steps of our computational procedure work with a fixed strike price $K$. In order to determine an optimal pair $\left(K^{*}, k^{*}\right)$ we perform a grid search on the interval of possible strike prices. The smallest (largest) $K$ we consider for the computations in Section 4 is typically $a_{2}^{s}-0.005$ $\left(a_{S-1}^{s}+0.005\right)$. We always use a step size of $10^{-3}$. In order to accelerate the computations in step 2 , it is useful to have a value for $k_{0}$ which is safely below $k^{*}$ but not too small. Typically, we use for $k_{0}$ the value 0.25 times the optimal fee from the previous grid point.

\section{B Running Times and Computational Errors}

When we solve the partial equilibrium problem we are concerned with three computational errors; the optimization error in the first-order conditions for the agents' maximization problems; the 
domain error in $k$ in the market maker's maximization problem; and the resulting error in the profit $P$. (We do not consider any error with respect to the strike price $K$, since we assume that it is unreasonable for the market maker to set real strike prices with many significant digits.)

We can easily control the relative error in $k$ by setting a desired value for $\epsilon$. For all the computations for which we report errors in Table 8 we use $\epsilon=10^{-10}$. When the interval size for $k$ is within this error tolerance the error in the objective function value is always below $0.01 \epsilon$. We report in Table 8 only the maximum relative error in the equilibrium equations for the finance economy.

Table 8 also reports running times for finding the optimal pair $\left(K^{*}, k^{*}\right)$ for some of the economies considered in Section $4.2(L=100, \mu=0.04)$. Computing such an optimal pair requires finding $k^{*}$ for 711 different strike prices (because of the way we set up step 2). The results indicate that the program is able to find the optimal $k^{*}$ for a single strike price $K$ is less than 0.6 seconds. The relative computational errors are consistently below $10^{-10}$.

\section{[TABLE 8 ABOUT HERE]}

\section{Computation of Wealth Equivalents}

In the finance model with incomplete markets the agents disagree on the state prices. As a consequence the concepts of equivalent variation and compensating variation are not well-defined for the incomplete-markets economies. Therefore we need to define another measure for wealth comparisons. For all wealth comparisons between the economies with and without the option exchange we define the following measure; the fraction of additional first-period consumption in the economy without the option exchange that would make the agent as well off as he is in the economy with the option exchange. Clearly, if the agent gains (loses) welfare through the option introduction then this fraction will be positive (negative).

Let $\Delta^{h}$ denote the difference between agent $h$ 's utility in the economy with the option and the economy without the option. Let $\delta^{h}$ be the fraction of additional first-period consumption in the no-option economy leading to the same utility as in the option economy. Let $v^{h}=u^{h}\left(c_{0}^{h}\right)$ be the first-period utility in the no-option equilibrium from consuming $c_{0}^{h}$. After computing the equilibria we know $\Delta^{h}$ and $v^{h}$. We can then compute $\delta^{h}$ by solving

$$
\Delta+v^{h}=u^{h}\left(\left(1+\delta^{h}\right) c_{0}^{h}\right)
$$


For log-utility it follows that

$$
\Delta+v^{h}=\ln \left(\left(1+\delta^{h}\right) c_{0}^{h}\right) \Longleftrightarrow \delta^{h}=-1+e^{\Delta^{h}} .
$$

For CRRA utility functions with $\gamma^{h} \neq 1$ the fraction equals

$$
\delta^{h}=-1+\left[1+\frac{\Delta^{h}}{v^{h}}\right]^{\frac{1}{1-\gamma^{h}}} .
$$

For our quadratic utility functions the fraction equals

$$
\delta^{h}=-1-\frac{1}{b c_{0}^{h}}-\sqrt{\frac{\left(b\left(c_{0}^{h}\right)^{2}+c_{0}^{h}\right)^{2}}{\left(b\left(c_{0}^{h}\right)^{2}\right)^{2}}+\frac{\Delta^{h}}{\frac{1}{2} b\left(c_{0}^{h}\right)^{2}}} .
$$

For CARA utility functions the fraction equals

$$
\delta^{h}=-\frac{\ln \left(\frac{\Delta^{h}+v^{h}}{v^{h}}\right)}{a c_{0}^{h}} .
$$

\section{References}

[1] Allen, F. and D.Gale, 1994, Financial Innovation and Risk Sharing, (MIT Press, Cambridge).

[2] Bisin, A., 1998, General Equilibrium with Endogenously Incomplete Financial Markets, Journal of Economic Theory 82, 19-45.

[3] Detemple, J. and P.Jorion, 1990, Option listing and stock returns: An empirical analysis, Journal of Banking and Finance 14, 781-801.

[4] Detemple, J. and L.Selden, 1991, A general equilibrium analysis of option and stock market interaction, International Economic Review 32, 279-303.

[5] Duffie, D., 1992, Dynamic Asset Pricing Theory, Princeton University Press, Princeton. 
[6] Duffie, D., 1993, The Nature of Incomplete Markets, in J.-J. Laffont, Advances in Economic Theory: Sixth World Congress, Cambridge University Press, Cambridge.

[7] Duffie, D. and Jackson, 1989, Optimal Innovation of Futures Contracts, Review of Financial Studies 2, 275-296.

[8] Duffie, D. and R.Rahi, 1995, Financial Market Innovation and Security Design, Journal of Economic Theory 65, 1-42.

[9] Elul, R., 1995, Welfare effects of financial innovations in incomplete markets with several consumption goods, Journal of Economic Theory 65, 43-78.

[10] Garcia, C. and W. Zangwill, 1981, Pathways to solutions, fixed points, and equilibria (Prentice Hall, Englewood Cliffs).

[11] Geanakoplos, J., 1990, An Introduction to General Equilibrium with Incomplete Asset Markets, Journal of Mathematical Economics 19, 1-38.

[12] Hara, C., 1995, Commission-Revenue Maximization in a General Equilibrium Model of Asset Creation, Journal of Economic Theory 65, 258-298.

[13] Herings, P.J.J. and K. Schmedders, 2000, Computing Equilibria in Finance Economies with Incomplete Markets and Transaction Costs, working paper, Northwestern University.

[14] Huang, P. and H.M. Wu, 1997, General Equilibrium with Incomplete Markets of European Options, working paper, Stanford University and National Taiwan University.

[15] Judd, K.L., 1998, Numerical Methods in Economics (MIT Press, Cambridge).

[16] Kubler, F. and K. Schmedders, 1998, Computing Equilibria in Stochastic Finance Economies, forthcoming in Computational Economics.

[17] Laitenberger, M., 1991, Existence of Financial Market Equilibria with Transaction Costs, Richerche Economiche 50, 69-77.

[18] Magill, M.J.M. and M. Quinzii, 1996, Theory of incomplete markets (MIT Press, Cambridge).

[19] Magill, M.J.M. and W. Shafer, 1991, Incomplete markets, in the Handbook of Mathematical Economics Volume IV, edited by W.Hildenbrand and H.Sonnenschein, North-Holland, New York (1991), 1523-1614. 
[20] Merton, R.C., 1990, The Financial System and Economic Performance, Journal of Financial Services Research 4, 263-300.

[21] Pesendorfer, W., 1995, Financial Innovation in a General Equilibrium Model, Journal of Economic Theory 65, 79-116.

[22] Polemarchakis, H. and B.Ku, Options and Equilibrium, Journal of Mathematical Economics $19,107-112$.

[23] Préchac, C., 1994, Existence of equilibrium in incomplete markets with intermediation costs, Journal of Mathematical Economics 25, 373-380.

[24] Ross, S.A., 1976, Options and efficiency, Quarterly Journal of Economics 90, 75-89.

[25] Schmedders, K., 1998, Computing Equilibria in the General Equilibrium Model with Incomplete Asset Markets, Journal of Economic Dynamics and Control 22, 1375-1401.

[26] Silber, W.L., 1981, Innovation, Competition, and New Contract Design in Futures Markets, Journal of Futures Markets 1, 123-155.

[27] Van Horne, J.C., 1985, Of Financial Innovation and Excesses, Journal of Finance 40, 621-631.

[28] Watson, L.T., S.C. Billups, and A.P. Morgan, 1987, HOMPACK: A Suite of Codes for Globally Convergent Homotopy Algorithms, ACM Transactions on Mathematical Software 13, 281-310.

[29] Yamazaki, A., 1991, Equilibrium in Economics with Incomplete Markets and Outside Money: Transaction Costs and Existence, working paper, Hitotsubashi University. 


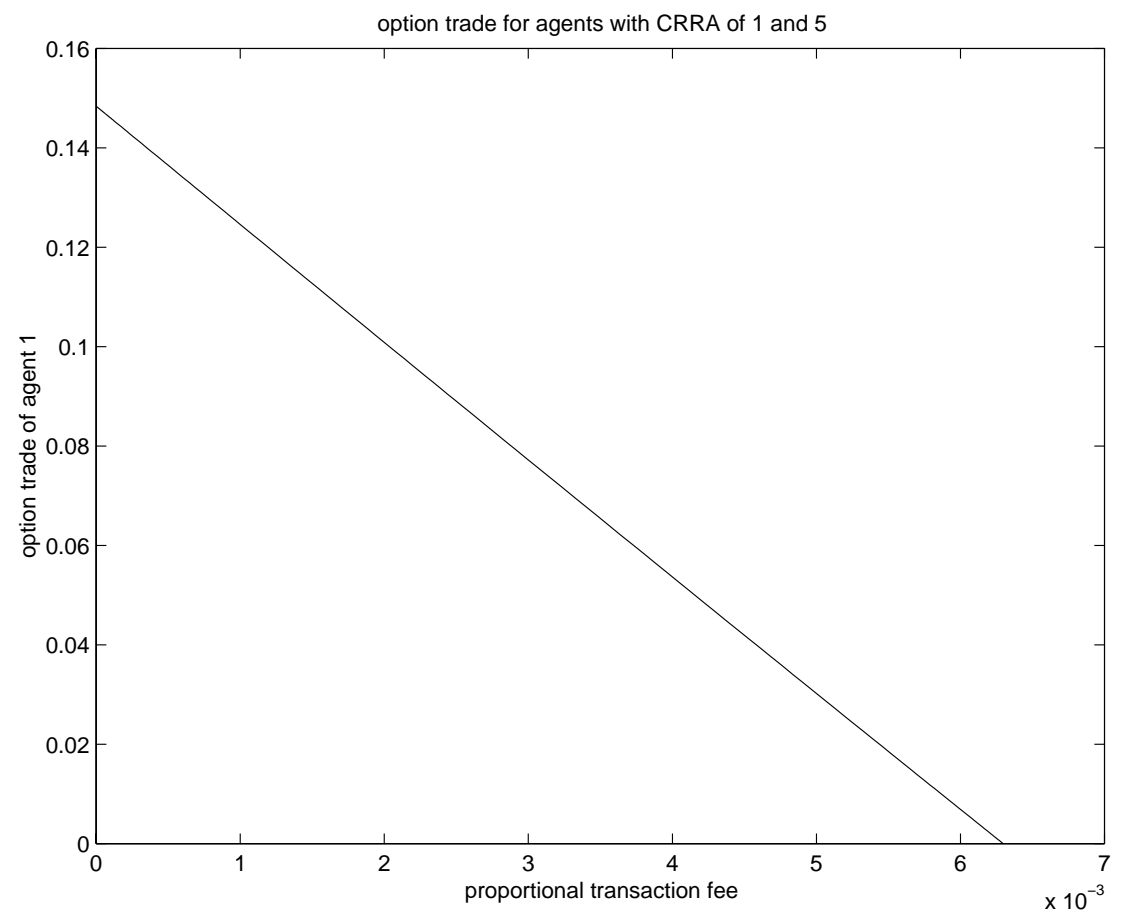

Figure 1: Option trades as a function of $k$. 


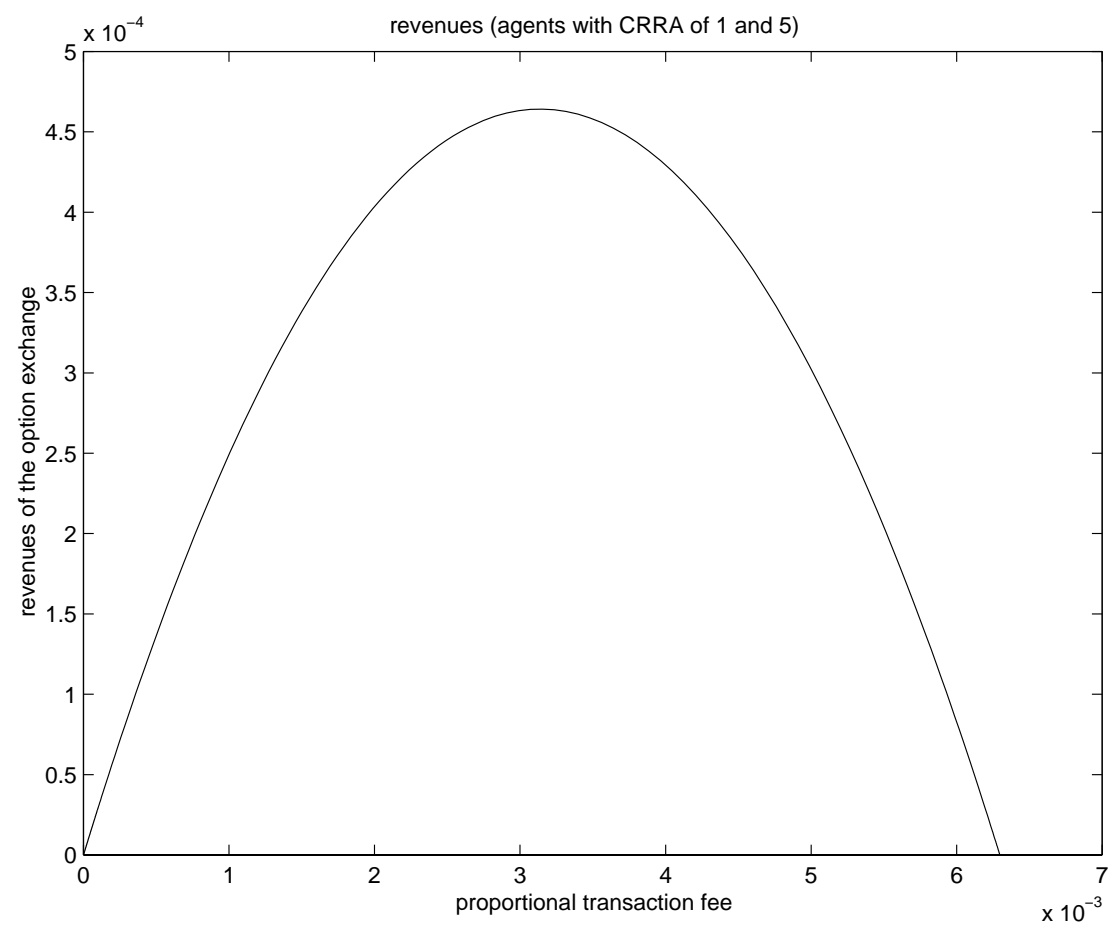

FiguRE 2: Revenues of the option exchange as a function of $k$. 


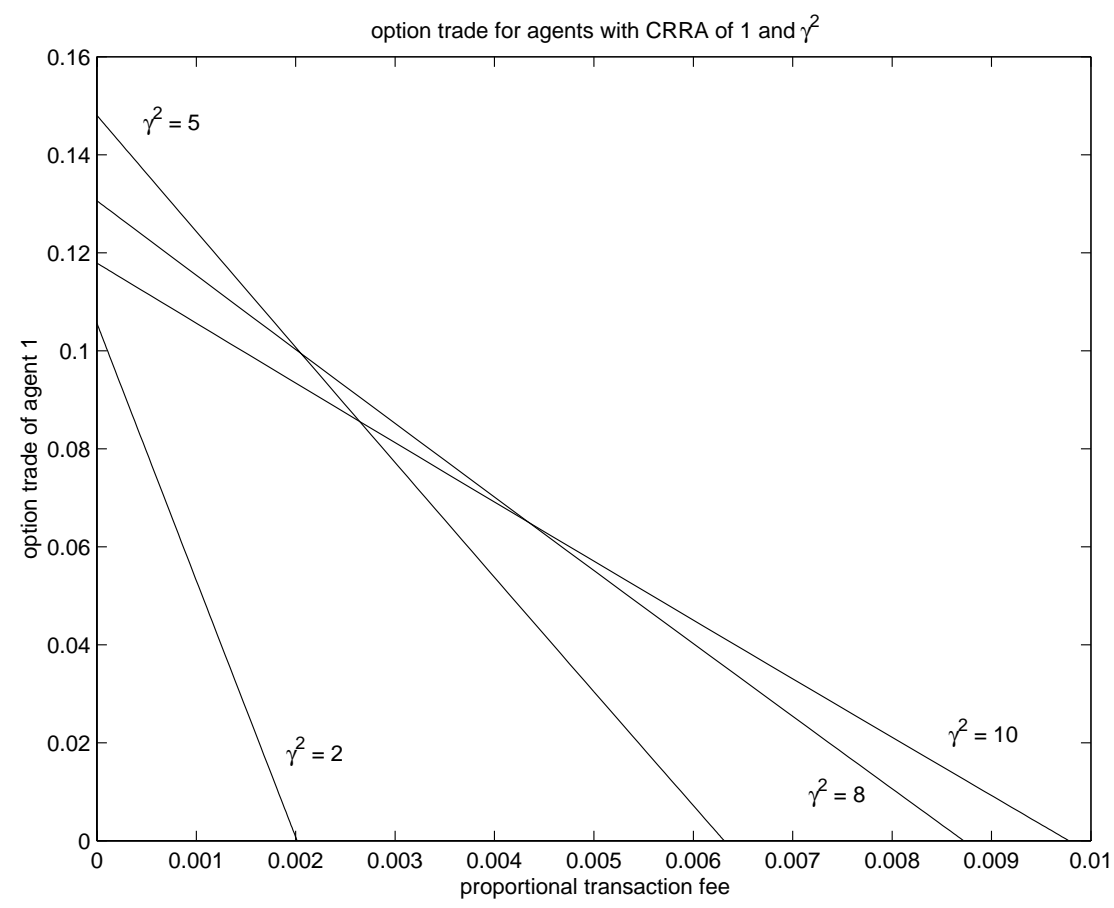

FiguRE 3: Illustration of Computational Result 1. 


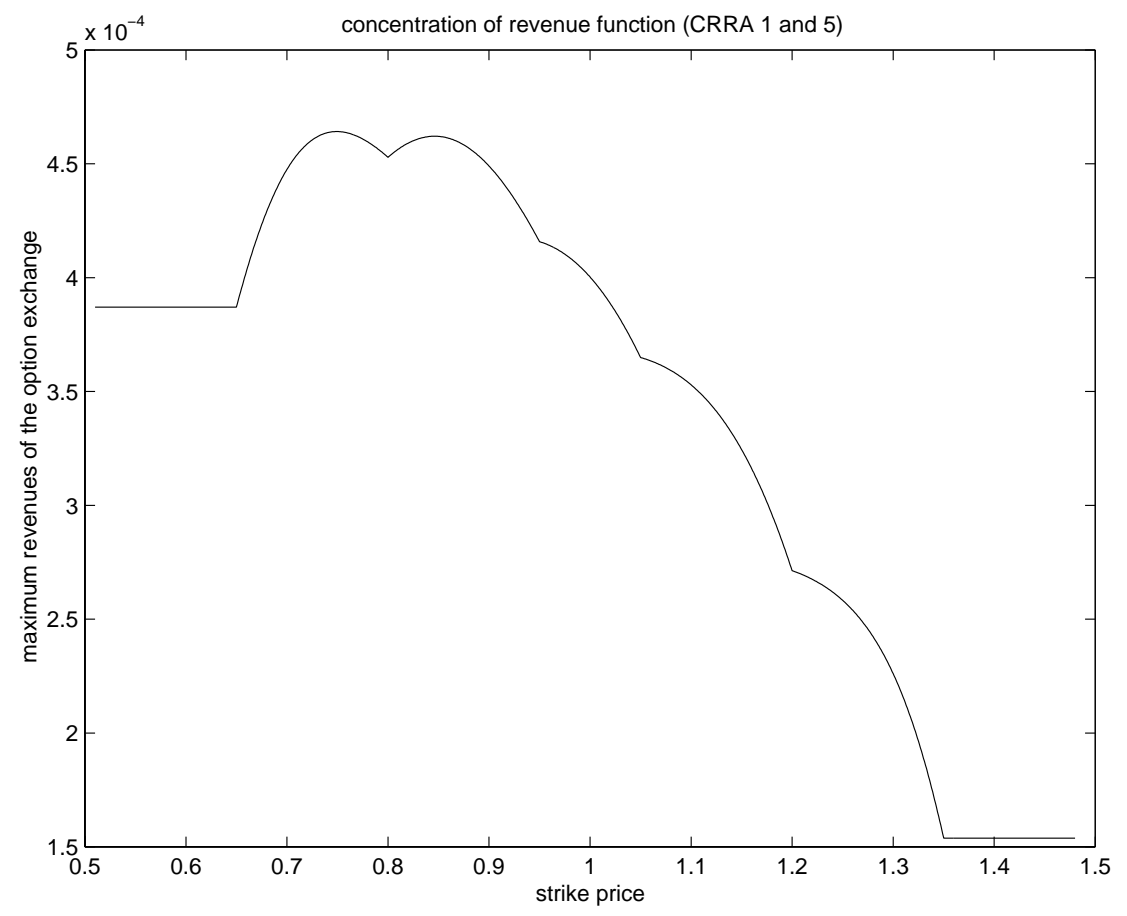

FIgURE 4: Concentration of the revenue function. 


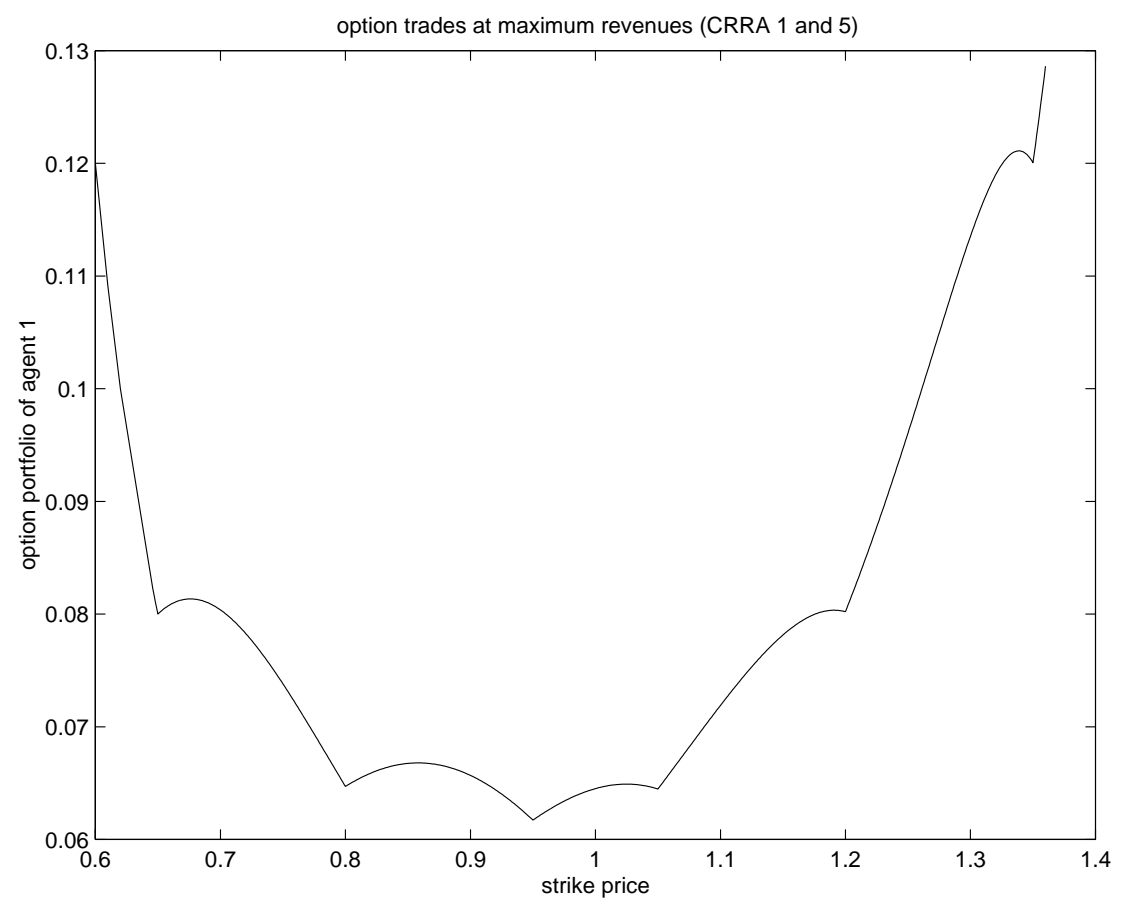

Figure 5: Option trades. 


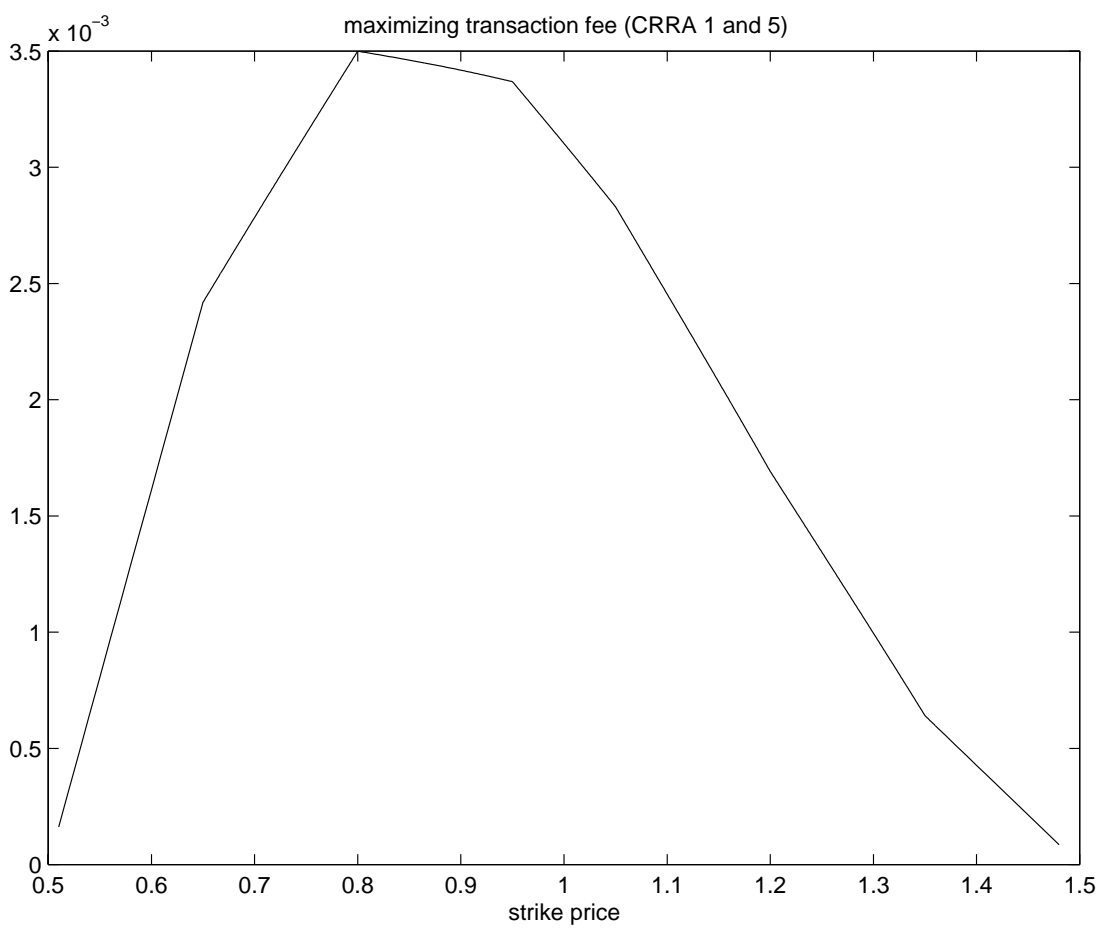

Figure 6: Profit-maximizing transaction fee. 


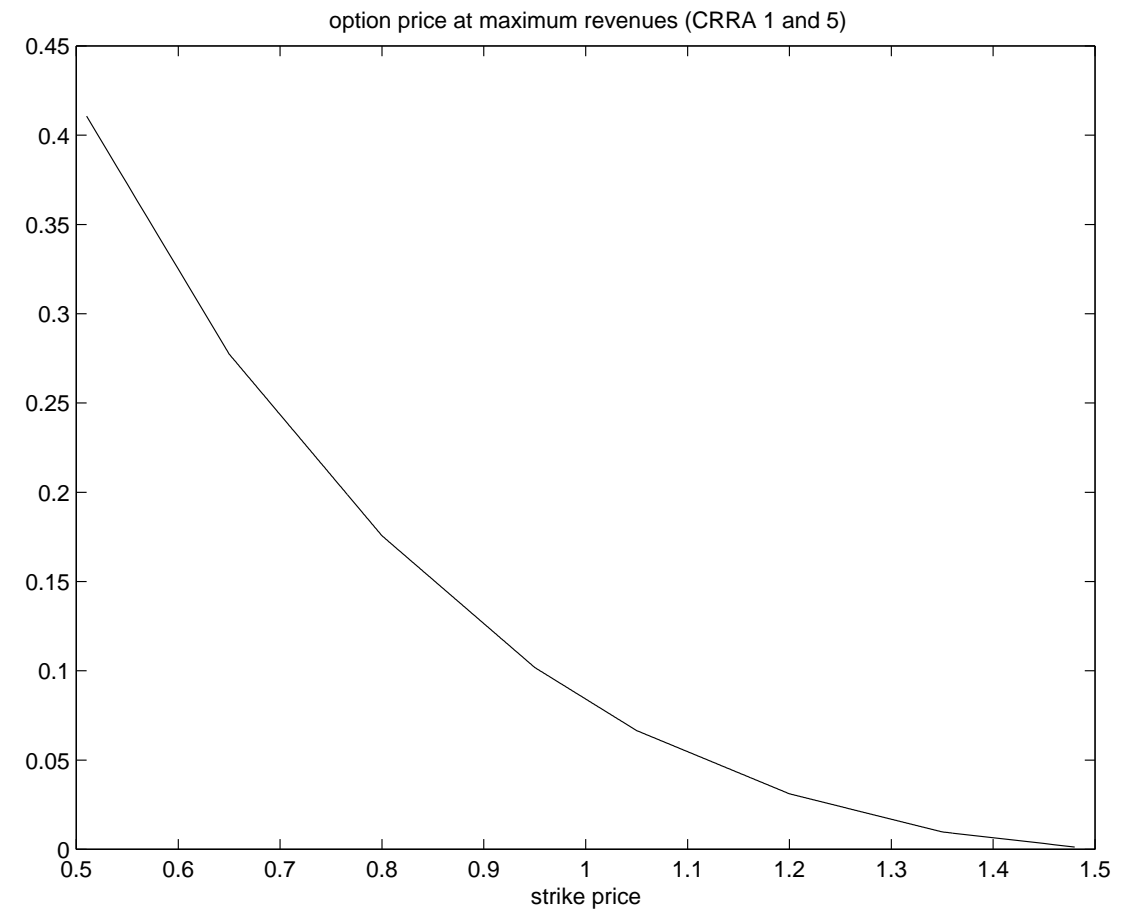

Figure 7: Option price. 


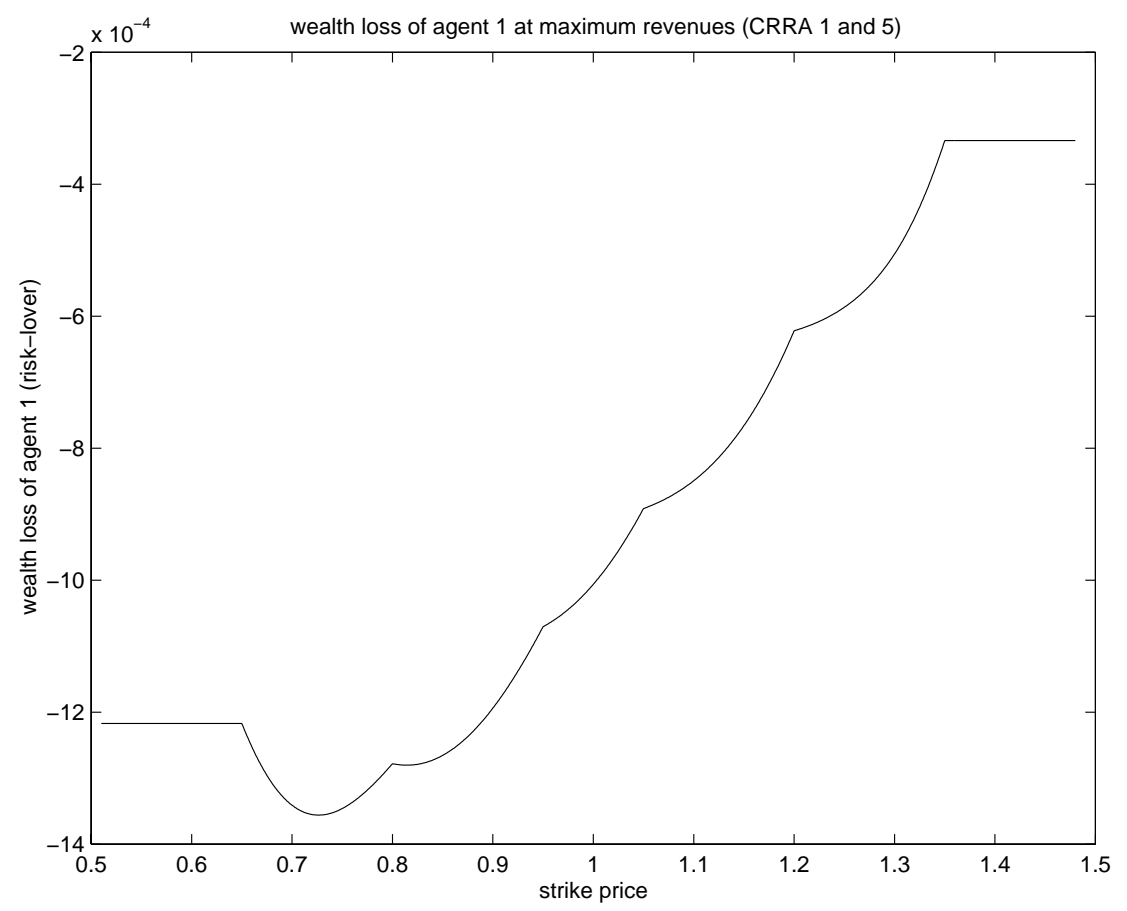

FiguRE 8: Welfare loss of agent 1 due to option introduction. 


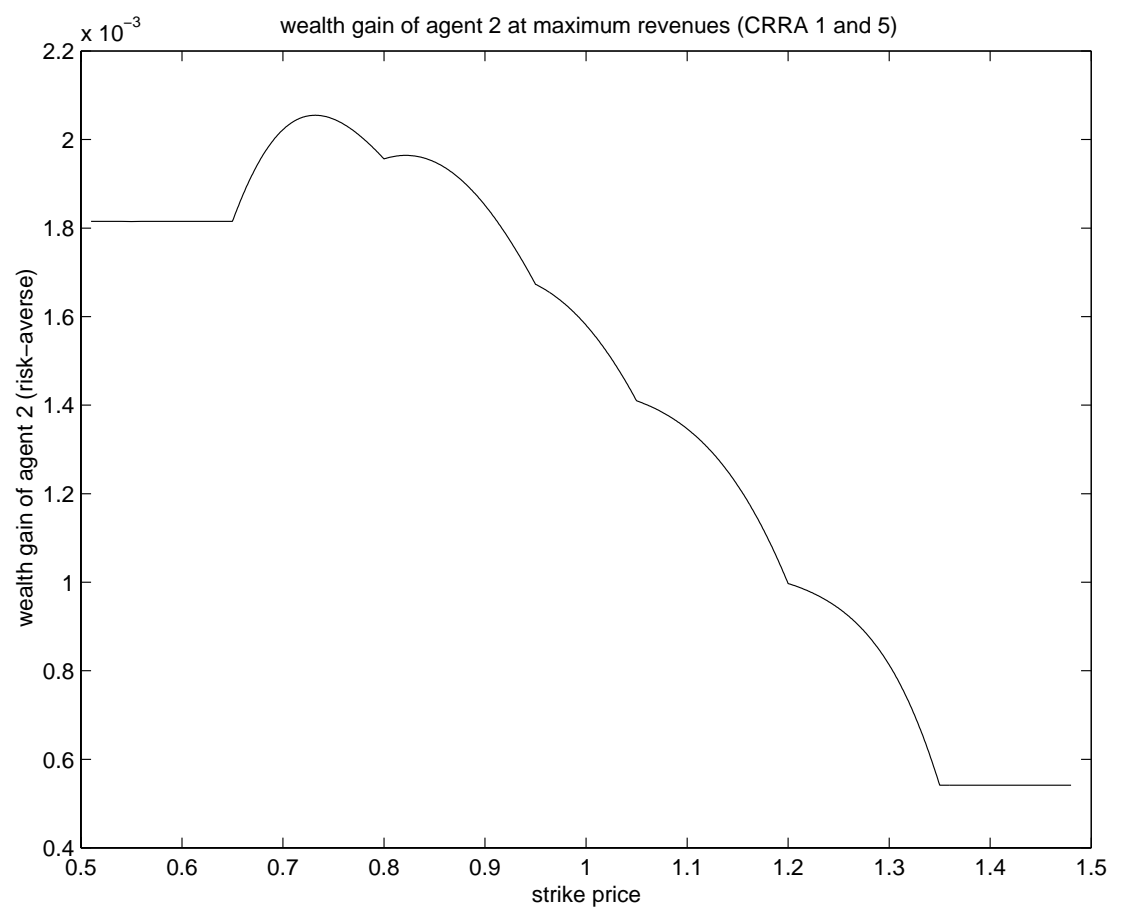

FiguRE 9: Welfare gain of agent 1 due to option introduction. 


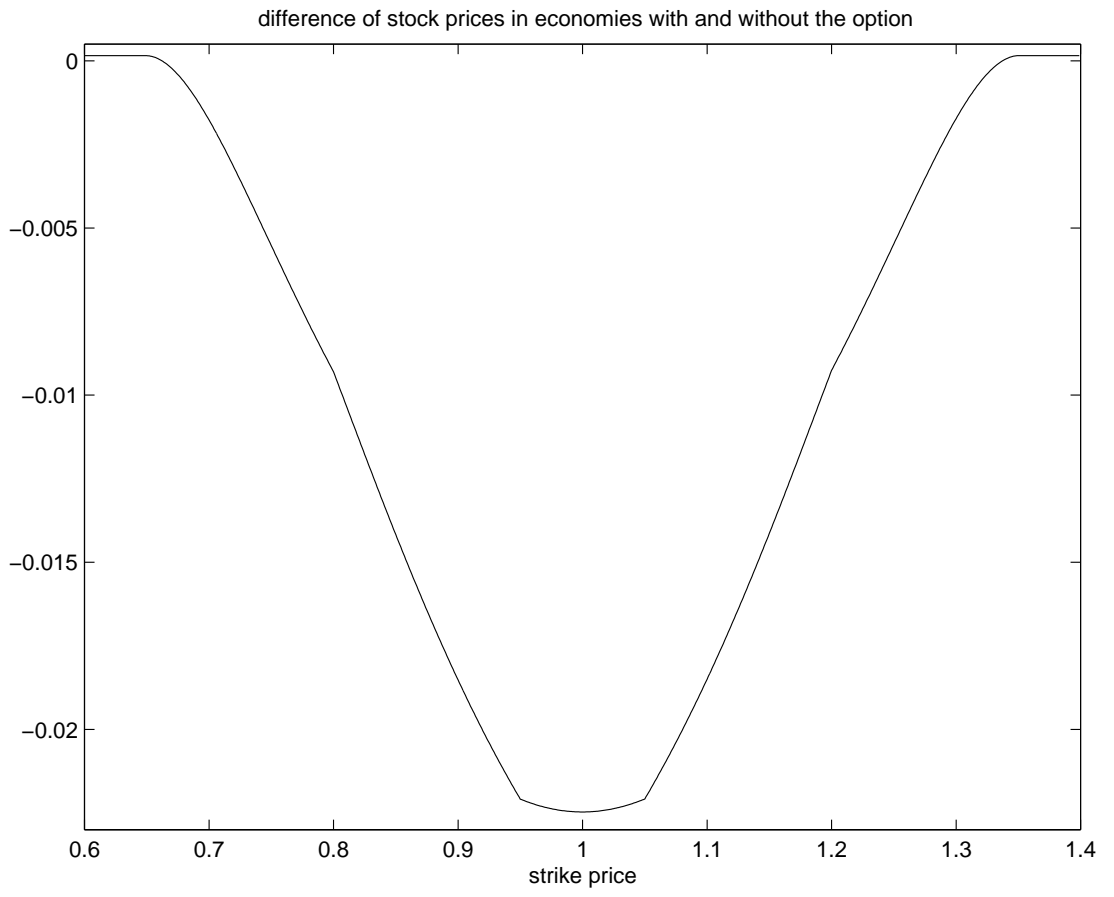

Figure 10: Stock price difference for beliefs $\Pi(6)$. 


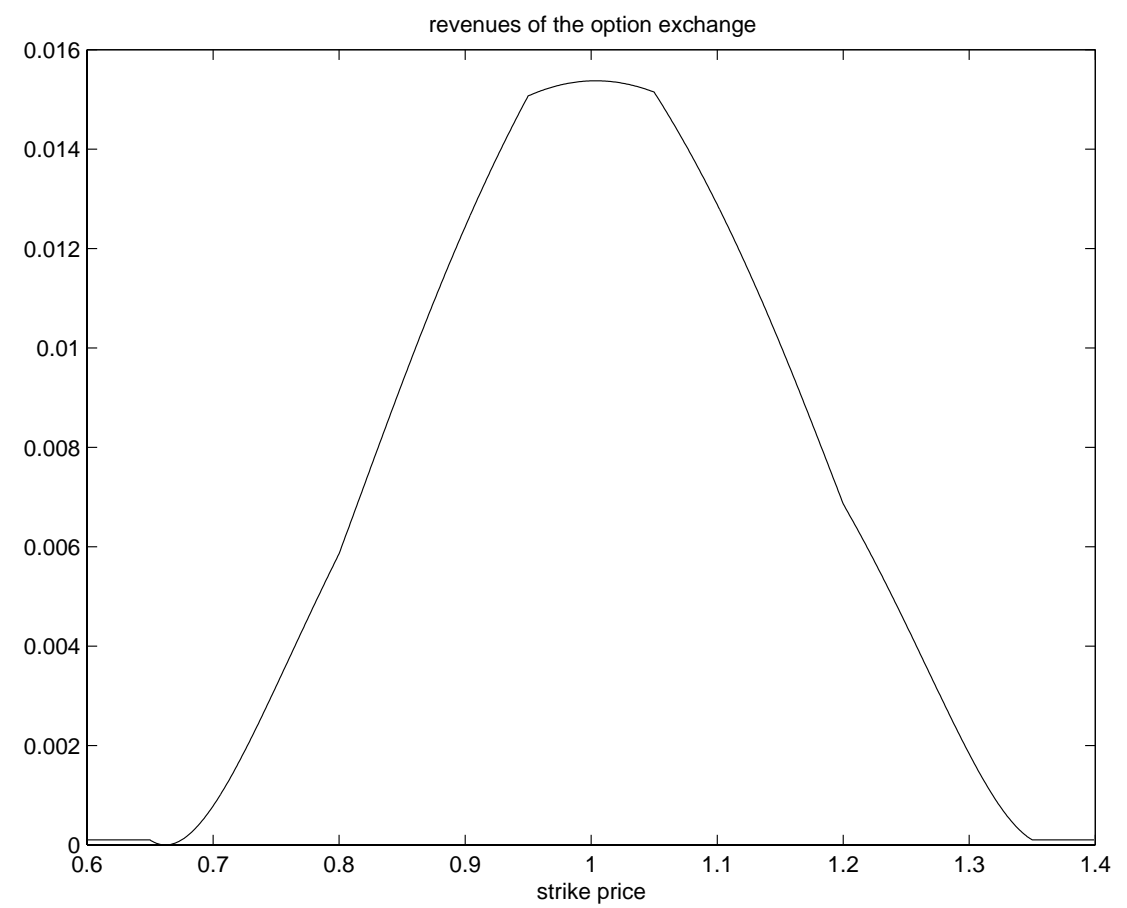

FiguRE 11: Revenue function of the option exchange for beliefs $\Pi(6)$. 


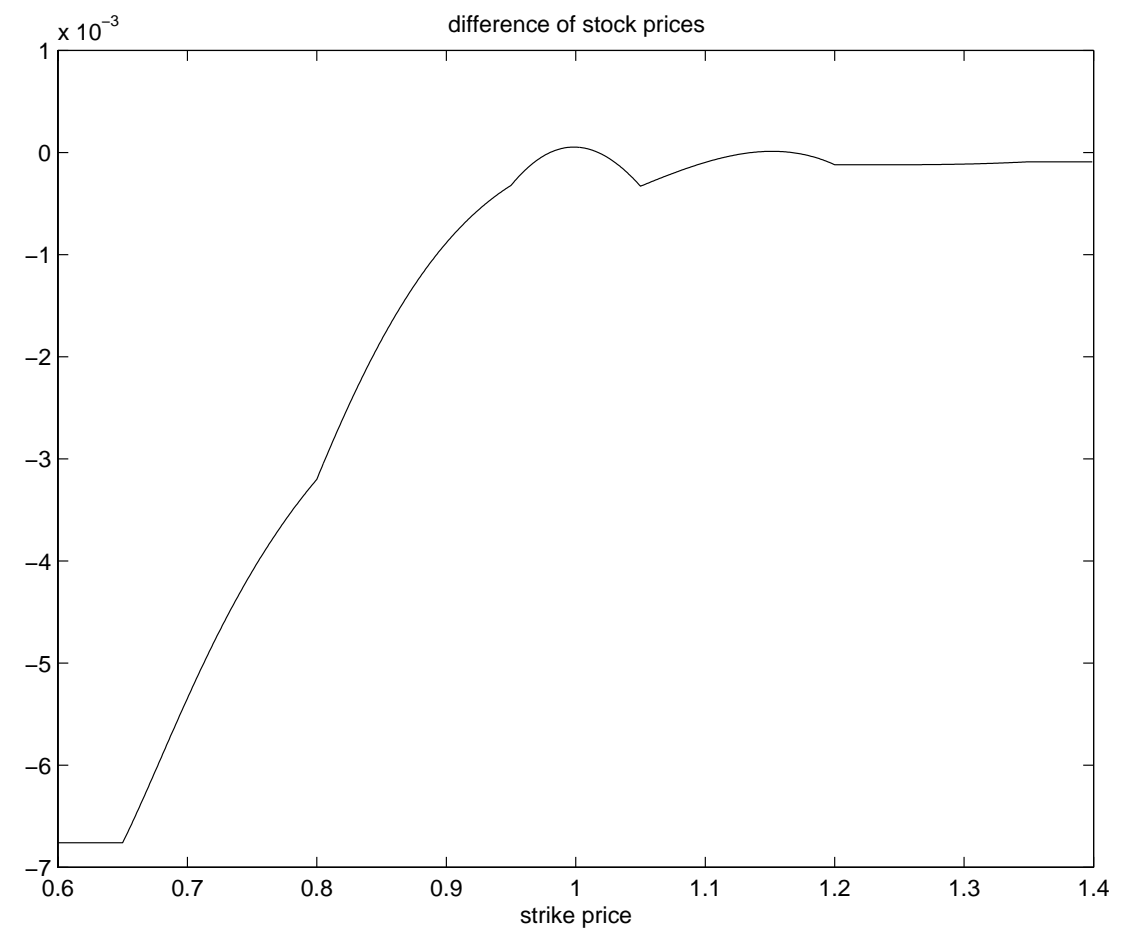

Figure 12: Stock price difference for beliefs $\Pi(7)$. 


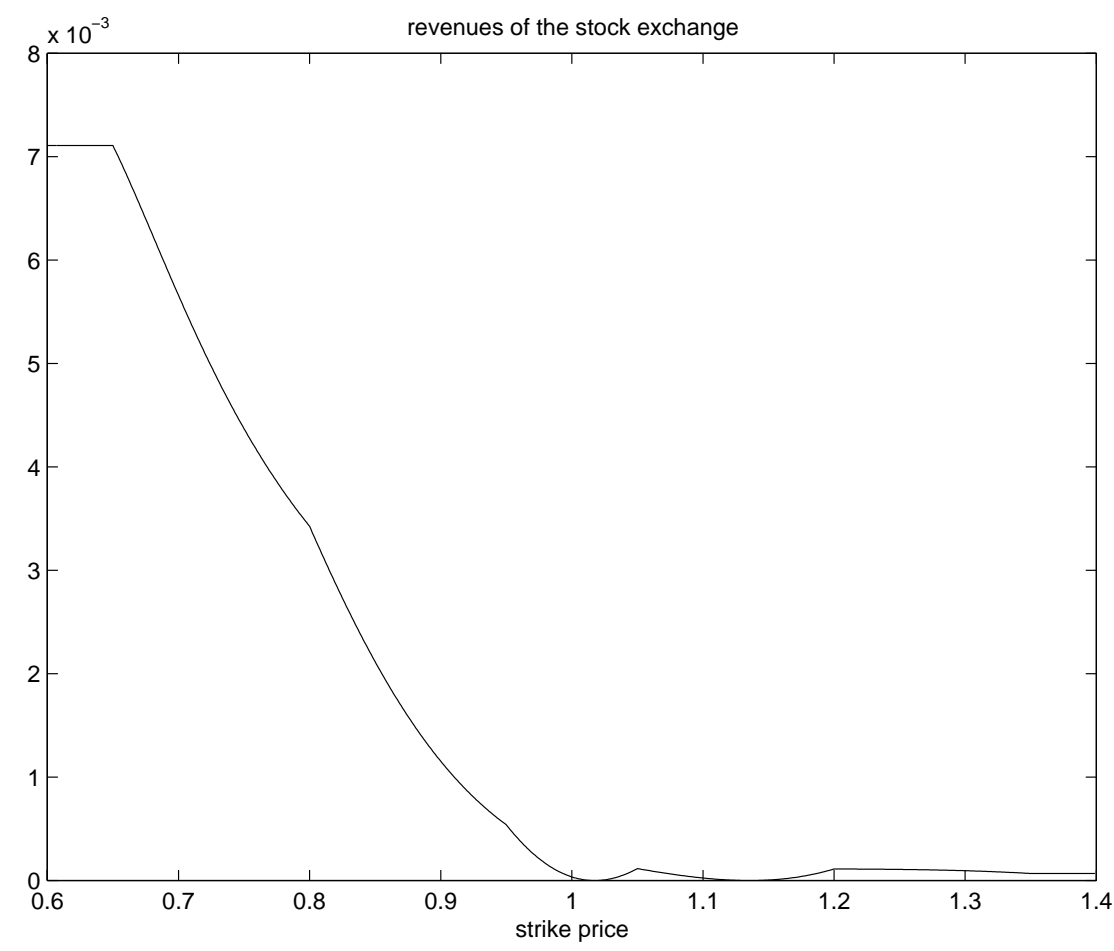

FiguRE 13: Revenues of the option exchange for beliefs $\Pi(7)$. 


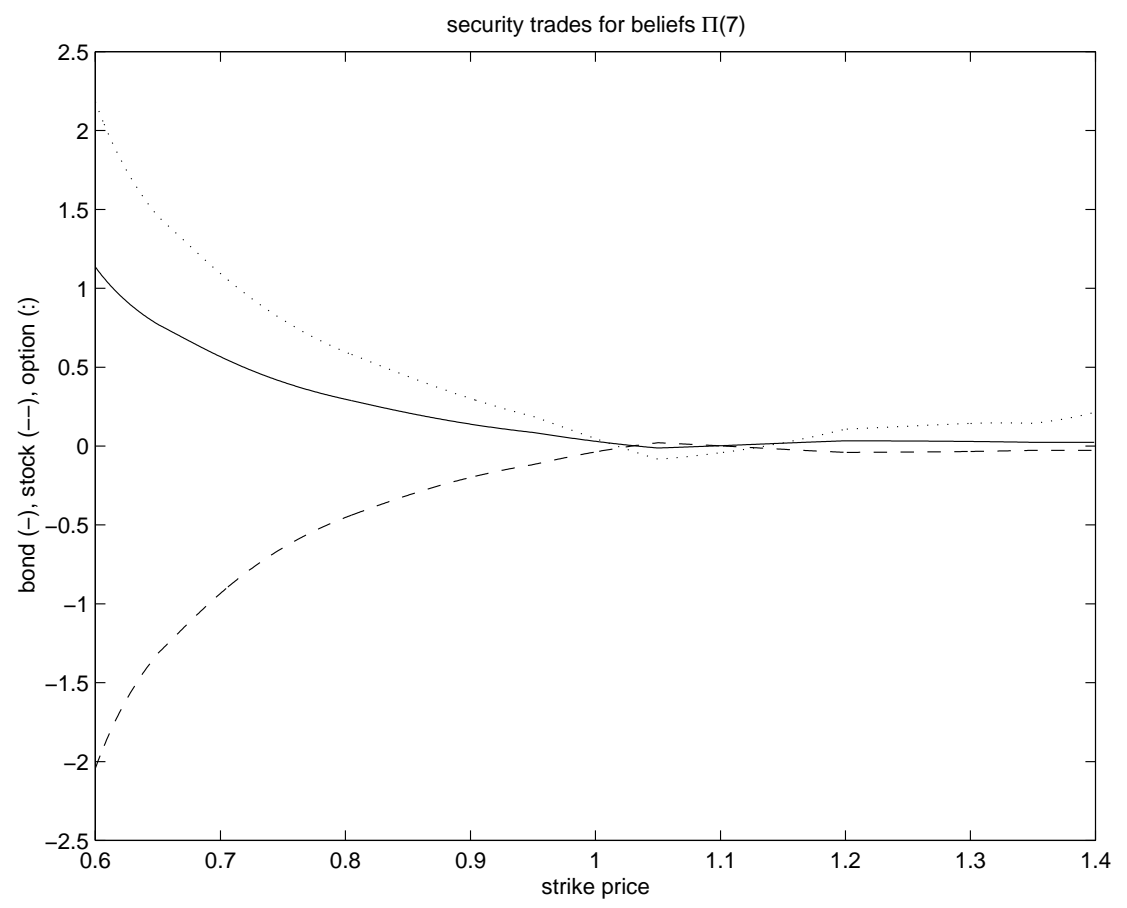

FiguRE 14: Security trades for beliefs $\Pi(7)$. 


\begin{tabular}{rr|rc|cc|ccc|r|}
\multicolumn{2}{r|}{$\gamma^{1}$} & $\gamma^{2}$ & \multicolumn{2}{|c|}{$\begin{array}{c}\text { trades of agent 1 } \\
\text { (no option) }\end{array}$} & \multicolumn{2}{|c|}{ option } & \multicolumn{2}{|c|}{ trades of agent 1} & \multicolumn{2}{|c|}{ with option } & revenues \\
& & bond & stock & strike & fee $\left(\cdot 10^{-3}\right)$ & bond & stock & option & $\left(\cdot 10^{-5}\right)$ \\
\hline 1 & 1.2 & -0.037 & 0.041 & 0.876 & 0.239 & -0.033 & 0.034 & 0.0144 & 0.686 \\
1 & 2 & -0.135 & 0.151 & 0.869 & 1.143 & -0.120 & 0.127 & 0.0486 & 11.105 \\
1 & 5 & -0.271 & 0.312 & 0.749 & 3.137 & -0.243 & 0.263 & 0.0740 & 46.419 \\
1 & 8 & -0.318 & 0.370 & 0.739 & 4.239 & -0.293 & 0.326 & 0.0667 & 56.546 \\
3 & 4 & -0.052 & 0.070 & 0.860 & 1.400 & -0.048 & 0.062 & 0.0222 & 6.206 \\
3 & 7 & -0.141 & 0.204 & 0.751 & 5.363 & -0.129 & 0.181 & 0.0488 & 52.329 \\
3 & 10 & -0.186 & 0.278 & 0.746 & 8.081 & -0.173 & 0.254 & 0.0526 & 85.032
\end{tabular}

TABLE 1: Revenue maximizing options as functions of $\gamma^{h}, h=1,2$.

\begin{tabular}{|c|c|c|c|c|c|c|c|c|c|}
\hline \multirow[t]{2}{*}{$\gamma^{1}$} & \multirow[t]{2}{*}{$\gamma^{2}$} & \multicolumn{2}{|c|}{$\begin{array}{c}\text { asset price } \\
\text { (change (in \%) w/o option) }\end{array}$} & \multirow{2}{*}{$\begin{array}{l}\text { option } \\
\text { strike }\end{array}$} & \multicolumn{3}{|c|}{$\begin{array}{l}\text { asset prices } \\
\text { with option }\end{array}$} & \multicolumn{2}{|c|}{$\begin{array}{l}\text { wealth change } \\
\left(\cdot 10^{-4}\right) \text { agent }\end{array}$} \\
\hline & & bond & stock & & bond & stock & option & 1 & 2 \\
\hline 1 & 1.2 & 0.004 & 0.002 & 0.876 & 1.150 & 1.006 & 0.156 & 0.006 & 0.062 \\
\hline 1 & 2 & 0.080 & 0.036 & 0.869 & 1.226 & 1.036 & 0.151 & -1.130 & 2.304 \\
\hline 1 & 5 & 0.420 & 0.241 & 0.749 & 1.417 & 1.129 & 0.210 & -13.467 & 20.471 \\
\hline 1 & 8 & 0.535 & 0.328 & 0.739 & 1.520 & 1.182 & 0.214 & -20.213 & 31.084 \\
\hline 3 & 4 & 0.046 & 0.038 & 0.860 & 2.567 & 1.688 & 0.098 & -0.054 & 0.699 \\
\hline 3 & 7 & 0.365 & 0.334 & 0.751 & 3.766 & 2.312 & 0.143 & -5.245 & 12.764 \\
\hline 3 & 10 & 0.557 & 0.530 & 0.746 & 4.595 & 2.742 & 0.142 & -10.712 & 26.380 \\
\hline
\end{tabular}

TABLE 2: Asset prices and wealth change as functions of $\gamma^{h}, h=1,2$. 


\begin{tabular}{|c|c|c|c|c|c|c|c|c|c|c|}
\hline \multirow[t]{2}{*}{ variance } & \multirow[t]{2}{*}{$\gamma^{1}$} & \multirow[t]{2}{*}{$\gamma^{2}$} & \multicolumn{2}{|c|}{$\begin{array}{l}\text { trades of agent } 1 \\
\text { (no option) }\end{array}$} & \multicolumn{2}{|c|}{ option } & \multicolumn{3}{|c|}{$\begin{array}{l}\text { trades of agent } 1 \\
\text { with option }\end{array}$} & \multirow{2}{*}{$\begin{array}{r}\text { revenues } \\
\left(\cdot 10^{-5}\right)\end{array}$} \\
\hline & & & bond & stock & strike & fee $\left(\cdot 10^{-4}\right)$ & bond & stock & option & \\
\hline \multirow[t]{6}{*}{0.035625} & 1 & 2 & -0.156 & 0.161 & 0.984 & 2.006 & -0.146 & 0.149 & 0.0269 & 1.077 \\
\hline & 1 & 5 & -0.313 & 0.326 & 0.976 & 5.403 & -0.301 & 0.310 & 0.0342 & 3.698 \\
\hline & 1 & 8 & -0.367 & 0.382 & 0.925 & 7.135 & -0.355 & 0.366 & 0.0284 & 4.048 \\
\hline & 3 & 4 & -0.064 & 0.070 & 0.981 & 2.212 & -0.061 & 0.065 & 0.0127 & 0.563 \\
\hline & 3 & 7 & -0.178 & 0.196 & 0.924 & 8.551 & -0.169 & 0.184 & 0.0277 & 4.737 \\
\hline & 3 & 10 & -0.239 & 0.266 & 0.872 & 12.098 & -0.225 & 0.247 & 0.0336 & 8.138 \\
\hline \multirow[t]{6}{*}{0.21} & 1 & 2 & -0.099 & 0.133 & 0.636 & 45.524 & -0.082 & 0.084 & 0.0810 & 73.771 \\
\hline & 1 & 5 & -0.191 & 0.294 & 0.603 & 158.757 & -0.168 & 0.222 & 0.1203 & 381.820 \\
\hline & 1 & 8 & -0.220 & 0.361 & 0.589 & 219.467 & -0.200 & 0.298 & 0.1026 & 450.364 \\
\hline & 3 & 4 & -0.035 & 0.080 & 0.625 & 71.016 & -0.031 & 0.068 & 0.0325 & 46.094 \\
\hline & 3 & 7 & -0.090 & 0.235 & 0.616 & 240.565 & -0.084 & 0.216 & 0.0656 & 315.671 \\
\hline & 3 & 10 & -0.114 & 0.311 & 0.613 & 329.532 & -0.109 & 0.294 & 0.0640 & 421.552 \\
\hline
\end{tabular}

TABLE 3: Revenue maximizing options as function of $\operatorname{Var}\left(a^{s}\right)$. 


\begin{tabular}{|c|c|c|c|c|c|c|c|c|c|c|}
\hline \multirow[t]{2}{*}{ variance } & \multirow[t]{2}{*}{$\gamma^{1}$} & \multirow[t]{2}{*}{$\gamma^{2}$} & \multicolumn{2}{|c|}{$\begin{array}{c}\text { asset price } \\
\text { (change (in \%) w/o option) }\end{array}$} & \multirow{2}{*}{$\begin{array}{l}\text { option } \\
\text { strike }\end{array}$} & \multicolumn{3}{|c|}{$\begin{array}{l}\text { asset prices } \\
\text { with option }\end{array}$} & \multicolumn{2}{|c|}{$\begin{array}{l}\text { wealth change } \\
\left(\cdot 10^{-5}\right) \text { agent }\end{array}$} \\
\hline & & & bond & stock & & bond & stock & option & 1 & 2 \\
\hline \multirow[t]{6}{*}{0.035625} & 1 & 2 & 0.008 & 0.004 & 0.984 & 1.064 & 1.011 & 0.0697 & -1.07 & 2.17 \\
\hline & 1 & 5 & 0.035 & 0.020 & 0.976 & 1.106 & 1.036 & 0.0693 & -9.63 & 13.76 \\
\hline & 1 & 8 & 0.043 & 0.027 & 0.925 & 1.126 & 1.049 & 0.0917 & -13.30 & 18.14 \\
\hline & 3 & 4 & 0.006 & 0.004 & 0.981 & 1.337 & 1.173 & 0.0489 & -0.06 & 0.63 \\
\hline & 3 & 7 & 0.053 & 0.043 & 0.924 & 1.531 & 1.306 & 0.0639 & -5.65 & 10.92 \\
\hline & 3 & 10 & 0.094 & 0.078 & 0.872 & 1.668 & 1.402 & 0.0892 & -14.69 & 24.86 \\
\hline \multirow[t]{6}{*}{0.21} & 1 & 2 & 0.510 & 0.229 & 0.636 & 1.689 & 1.091 & 0.2901 & -74.58 & 159.88 \\
\hline & 1 & 5 & 2.292 & 1.475 & 0.603 & 2.574 & 1.365 & 0.2937 & -842.66 & 1815.91 \\
\hline & 1 & 8 & 2.294 & 1.635 & 0.589 & 3.094 & 1.526 & 0.2980 & -1001.30 & 2705.42 \\
\hline & 3 & 4 & 0.212 & 0.213 & 0.625 & 9.793 & 3.667 & 0.2068 & -1.64 & 53.23 \\
\hline & 3 & 7 & 1.347 & 1.403 & 0.616 & 18.580 & 6.412 & 0.1964 & -138.35 & 745.32 \\
\hline & 3 & 10 & 1.735 & 1.817 & 0.613 & 23.513 & 7.921 & 0.1890 & -182.91 & 1226.21 \\
\hline
\end{tabular}

TABLE 4: Asset prices and wealth changes as function of $\operatorname{Var}\left(a^{s}\right)$. 


\begin{tabular}{c|rr|rr|rrr|r|}
\multirow{2}{*}{ beliefs } & \multicolumn{2}{|c|}{$\begin{array}{c}\text { trades of agent 1 } \\
\text { (no option) }\end{array}$} & \multicolumn{2}{|c|}{ option } & \multicolumn{2}{|c|}{ trades of agent 1 } & \multicolumn{2}{|c|}{ with option } \\
& bond & stock & strike & fee $\left(\cdot 10^{-3}\right)$ & bond & stock & option & $\left(\cdot 10^{-3}\right)$ \\
\hline$\Pi(1)$ & -0.0417 & 0.0427 & 0.889 & 3.447 & -0.314 & 0.431 & -0.601 & 4.141 \\
$\Pi(2)$ & -0.0306 & 0.0313 & 0.976 & 2.826 & -0.187 & 0.245 & -0.402 & 2.271 \\
$\Pi(3)$ & 0.0270 & -0.0278 & 0.976 & 2.824 & 0.178 & -0.241 & 0.402 & 2.269 \\
$\Pi(4)$ & 0.0353 & -0.0363 & 0.903 & 3.514 & 0.282 & -0.398 & 0.581 & 4.080 \\
\hline$\Pi(5)$ & -0.0425 & 0.0441 & 0.997 & 7.435 & -0.455 & 0.682 & -1.268 & 18.851 \\
$\Pi(6)$ & -0.0403 & 0.0418 & 1.004 & 7.446 & -0.379 & 0.553 & -1.033 & 15.376
\end{tabular}

TABLE 5: Revenue maximizing options as a function of beliefs $\Pi$.

\begin{tabular}{c|lc|c|ccc|cc|} 
& \multicolumn{2}{|c|}{$\begin{array}{c}\text { asset price } \\
\text { beliefs }\end{array}$} & $\begin{array}{c}\text { (change (in \%) w/o option) } \\
\text { bond }\end{array}$ & option & \multicolumn{3}{c|}{ asset prices } & \multicolumn{2}{c|}{ wealth change } \\
& stock & strike & bond & stock & option & 1 & 2 \\
\hline$\Pi(1)$ & 0.614 & 0.613 & 0.889 & 0.994 & 0.947 & 0.162 & 2.021 & 2.139 \\
$\Pi(2)$ & 0.340 & 0.349 & 0.976 & 0.997 & 0.948 & 0.118 & 1.128 & 1.149 \\
$\Pi(3)$ & 0.340 & 0.351 & 0.976 & 0.997 & 0.942 & 0.126 & 1.127 & 1.148 \\
$\Pi(4)$ & 0.608 & 0.616 & 0.903 & 0.994 & 0.939 & 0.163 & 2.032 & 2.066 \\
\hline$\Pi(5)$ & 2.899 & 3.056 & 0.997 & 0.972 & 0.900 & 0.138 & 21.213 & 6.384 \\
$\Pi(6)$ & 2.354 & 2.476 & 1.004 & 0.977 & 0.907 & 0.129 & 10.006 & 5.616
\end{tabular}

TABLE 6: Asset prices and wealth change as functions of beliefs $\Pi$. 


\begin{tabular}{l|c|c|c}
\multicolumn{4}{c}{ revenue-maximizing strike prices } \\
belief & $\begin{array}{c}\text { CRRA } \\
\gamma_{1}=\gamma_{2}=1\end{array}$ & $\begin{array}{c}\text { quadratic } \\
b=\frac{2}{3}\end{array}$ & $\begin{array}{c}\text { CARA } \\
\text { ח }\end{array}$ \\
\hline$\Pi(1)$ & 1.141 & 0.889 & 0.999 \\
$\Pi(2)$ & 1.048 & 0.976 & 0.999 \\
$\Pi(3)$ & 1.050 & 0.976 & 1.001 \\
$\Pi(4)$ & 1.134 & 0.903 & 1.001 \\
\hline$\Pi(5)$ & 1.050 & 0.997 & 1.030 \\
$\Pi(6)$ & 1.050 & 1.004 & 1.029
\end{tabular}

TABLE 7: Strike prices as functions of preferences and beliefs $\Pi$.

running times and errors

\begin{tabular}{ll|c|c}
$\gamma^{1}$ & $\gamma^{2}$ & r. t. (mm:ss) & max. relative opt. error \\
\hline 1 & 1.2 & $5: 28$ & $1.9 \cdot 10^{-12}$ \\
1 & 2 & $5: 34$ & $5.2 \cdot 10^{-13}$ \\
1 & 5 & $6: 23$ & $2.2 \cdot 10^{-13}$ \\
1 & 8 & $7: 07$ & $4.8 \cdot 10^{-13}$ \\
3 & 4 & $5: 51$ & $6.4 \cdot 10^{-13}$ \\
3 & 7 & $6: 57$ & $7.1 \cdot 10^{-12}$ \\
3 & 10 & $7: 46$ & $7.5 \cdot 10^{-12}$
\end{tabular}

TABLE 8: Running Times and Computational Errors. 